NBER WORKING PAPER SERIES

ECONOMIC GROHTH AND CONVERGENCE ACROSS THE UNITED STATES

Robert J. Barro

Xavier Sala 1 Martin

Working Paper No. 3419

NATIONAL BUREAU OF ECONOMIC RESEARCH

1050 Massachusetts Avenue

Cambridge, MA 02138

August 1990

\footnotetext{
We have benefited from research support by the National sclence Foundation, the Bradley Foundation, and the Hoover Institution. We appreclate helpful comments from Susan Guthrle, Greg Mankiw, Anne Krueger, and Sergio Rebelo. This paper is part of NBER's research program in Economic Growth. Any opinions expressed are those of the authors and not those of the National Bureau of Economic Research.
} 
NBER Working Paper \#3419

August 1990

\title{
ECONOMIC GROWTH AND CONVERGENCE
}

ACROSS THE UNITED STATES

\begin{abstract}
A key economic issue 18 whether poor countries or regions tend to grow faster than rich ones: are there automatic forces that lead to convergence over time in levels of per capita income and product? After considering predictions of closed- and open-economy neoclassical growth theorles, we examine data since 1840 from the U.S. states. We find clear evidence of convergence, but the findings can be reconciled quantitatively with neoclassical models only if diminishing returns to capital set in very slowly. The results from a broad sample of countries are similar if we hold constant a set of variables that proxy for differences in steady-state characteristics. Two types of existing theorles seem to fit the facts: the neoclassical growth model with broadly-defined capital and a limited role for diminishing returns, and endogenous growth models with constant returns and gradual diffusion of technology across economies.
\end{abstract}

Robert J. Barro Department of Economics Littauer Center 120 Harvard University Cambridge, MA 02138
Xavier Sala 1 Martin Department of Economics Iltauer Center 120 Harvard University Cambridge, MA 02138 
A key economic issue is whether poor countries or regions tend to grow faster than rich ones: are there automatic forces that lead to convergence over time in the levels of per capita income and product? We begin by considering the theoretical predictions about convergence from the standard neoclassical growth model of a closed economy. Because of diminishing returns to capital, poor economies have high rates of return and therefore tend to grow faster than rich economies. In international extensions of the neoclassical model, the convergence effect is reinforced by the movement of capital and technology from rich economies to poor and of labor from poor economies to rich.

Our main $\epsilon$ mpirical analysis deals with the growth of per capita income and product for the U.S. states. We exploit data on personal income back as far as 1840 and on gross state product since 1963. For studying the determinants of economic growth, the experience of the U.S. states represents a vastly underutilized resource: in effect, we have over a century of data on 48 economies (although surely not 48 closed economies!). We find that the U.S. states provide clear evidence for the existence of convergence in the sense of poor economies tending to grow faster than rich ones in per capita terms. But the observed speeds of convergence can be reconciled with the neoclassical growth model for closed economies only if we assume values for the underlying parameters of preferences and technology that depart substantially from usual benchmark cases. In particular, the model requires a high capital-share coefficient-in the neighborhood of 0.8 - so that diminishing returns to capital set in slowly as an economy develops. The required capital-share coefficient becomes even higher if we allow for open-economy features, which would be important for the U.S states.

We compare our findings for the U.S. states with results from a cross-country sample. Simple regressions for the growth rate of real per capita GDP from 1960 to 1985 for 98 countries indicate lack of convergence. The initially rich countries (in 1960) tended to grow at least as fast in per capita terms as the initially poor countries. We then add some additional explanatory variables, such as starting values of school- 
enrollment rates and average ratios of government consumption spending to GDP, which we argue hold constant cross-country differences in steady-state values of output per effective worker and the growth rate of technology. In these extended regressions, we find that the estimated convergence coefficients are similar to those revealed by the U.S. states. Thus, there is evidence of convergence, but a reconciliation with the neoclassical growth model again requires a high capital-share coefficient.

The empirical results push us toward growth models that view capital broadly to include human capital, so that diminishing returns to capital set in slowly if at all. Two existing models stand out as candidates for fitting the facts on convergence: the neoclassical growth model with a limited role for diminishing returns and endogenous growth models with roughly constant returns to capital. In the latter model, the convergence effects that we isolate would have to be explained by the gradual diffusion of technology across economies.

\section{Convergence in the Neoclassical Growth Model}

In neoclassical growth models for closed economies, as presented by Ramsey (1928), Solow (1956), Cass (1965), and Koopmans (1965), the per capita growth rate tends to be inversely related to the starting level of output per person. In particular, if countries are similar in respect to preferences and technology, then poor countries tend to grow faster than rich countries. Thus, there is a force that promotes convergence in levels of per capita income. In this section, we quantify this type of convergence effect from the neoclassical model. We begin with a sketch of the standard model; further detail appears, for example, in Sala i Martin (1989).

The production function for the representative producer is

$$
Y=F\left(K, L e^{g t}\right)
$$


where $\mathrm{Y}$ is the flow of output, $\mathrm{K}$ is the stock of capital, $\mathrm{e}^{\mathrm{gt}}$ represents the effect of exogenous labor-augmenting technological progress, and $\mathrm{L}$ is the labor force. Because we neglect labor-leisure choices and also assume full employment, we treat the labor force and population as equivalent. The key force that underlies the convergence effect is diminishing returns to reproducible capital. That is, we make the usual assumption that $F(\cdot)$ exhibits positive and diminishing marginal products in each input, as well as constant returns to scale. Equation (1) can then be rewritten as

$$
\hat{y}=f(\hat{k})
$$

where the symbol ` denotes a quantity per unit of effective labor, Le ${ }^{\mathrm{gt}}$, and $\mathrm{f}(\cdot)$ satisfies $\mathrm{f}^{\prime}>0$ and $\mathrm{f}^{\prime \prime}<0$.

Output in a closed economy can be used for investment, $\dot{K}$, or consumption, $\mathrm{C}$. If depreciation of capital is proportional at rate $\delta$, then $\hat{\mathrm{k}}$ evolves in accordance with

$$
\dot{\hat{k}}=f(\hat{\mathrm{k}})-\hat{\mathrm{c}}-(\mathbf{n}+\mathrm{g}+\delta) \hat{\mathrm{k}}
$$

where $\hat{c}=\mathrm{C} / \mathrm{Le}^{\mathrm{gt}}$ and $\mathrm{n}$ is the exogenous growth rate of population and hence, of the labor force, $\mathrm{L}$.

The representative, infinite-horizon household seeks to maximize utility, as given by

$$
U=\int_{0}^{\infty} u(c) e^{n t} e^{-\rho t} d t
$$

where $\mathrm{c}=\mathrm{C} / \mathrm{L}$ and $\rho$ is the constant rate of time preference. (We assume that $\rho$ is high 
enough so that the maximum attainable utility is finite.) The formulation assumes that the household cares about per capita utility, $u(c)$, multiplied by the membership of the family, which grows as $\mathrm{e}^{\mathrm{nt}}$. We assume that the momentary utility function takes the form

$$
u(c)=\frac{c^{1-\theta}-1}{1-\theta}
$$

with $\theta>0$, so that marginal utility, $u^{\prime}(c)$, has the constant elasticity $-\theta$ with respect to c. As $\theta$ tends to one, $u(c)$ tends to $\log (c)$.

As is well known, the first-order condition for maximizing $U$ in equation (4) entails

$$
\dot{c} / c=(1 / \theta) \cdot\left[f^{\prime}(\dot{k})-\delta-\rho\right]
$$

The maximization also involves a transversality condition, which ensures that the capital stock grows asymptotically at a rate less than the rate of return, $\mathrm{f}^{\prime}(\hat{\mathrm{k}})$. (This result requires $\rho>n+(1-\theta) g$.)

In the steady state, the effective quantities, $\hat{y}, \hat{k}$, and $\hat{c}$, do not change. Therefore, the per capita quantities, $y, k$, and $c$, each grow at the rate of exogenous technological progress, $g$. The absolute quantities, $Y, K$, and $C$, grow at the rate $g+n$. The level of $\dot{k}$ in the steady state follows by equating $c / c$ to $g$ in equation (6). Hence, using an asterisk to denote a steady-state value,

$$
\mathrm{f}^{\prime}\left(\hat{\mathrm{k}}^{*}\right)=\delta+\rho+\theta \mathrm{g}
$$


The level of $\hat{y}$ follows from $\hat{y}=f(\hat{k})$ and the level of $\hat{c^{*}}$ comes from setting the expression in equation (3) to zero.

If a country or region - which we treat as a closed economy - starts with $\hat{\mathrm{k}}$ below $\hat{\mathrm{k}}^{*}$, then equations (3) and (6) determine the dynamics of $\hat{\mathrm{k}}, \hat{\mathrm{y}}$, and $\hat{\mathrm{c}}$. The transversality condition implies that $\hat{k}$ follows the stable, saddle path and thereby monotonically approaches $\hat{k}^{*}$ (see Blanchard and Fischer [1989, Ch. 2]). Equation (6) implies that the growth rate of $\mathrm{c}$ is monotonically decreasing in $\hat{\mathrm{k}}$. That is, poorer countries, which have lower values of $\hat{k}$ and therefore higher values of the rate of return, $\mathrm{f}^{\prime}(\hat{\mathrm{k}})$, have higher growth rates of per capita consumption.

Because $\hat{k}$ rises along the transition path, the per capita quantities $k$ and $y$ must grow at rates that exceed the steady-state value, $g$. It follows that the growth rates of $\mathrm{k}$ and $\mathrm{y}$ decline with $\hat{\mathrm{k}}$ in some neighborhood of the steady state. These growth rates need not, however, be monotonically decreasing in $\hat{k}$ throughout the whole range of $\hat{k}$. That is, although the general tendency is for poorer countries to grow at higher rates, it is possible to find a reverse pattern over some ranges of $\hat{k}$. These reversals can arise because of the dependence of the saving rate, $s \equiv[f(\hat{k})-\hat{c}] / f(\hat{k})$, on $\hat{k}$. In the Solow (1956) model, where $s$ is arbitrarily assumed to be constant, the term, $f(\hat{k})-\hat{c}$, in equation (3) can be replaced by $\operatorname{sf}(\hat{k})$. It can then be shown readily that the growth rates of $\hat{k}$ and $\hat{y}$ are each monotonically decreasing in $\hat{k}$. That is, in the Solow model, poor countries unambiguously grow faster than rich countries.

If the saving rate fell as $\hat{\mathrm{k}}$ rose-which might be expected from the decline in the rate of return, $f^{\prime}(\hat{k})$ - then the tendency for growth rates to decline with $\hat{k}$ would be reinforced. Thus, growth rates decline with $\hat{k}$ unless the saving rate rises substantially (because of the income effect from an increase in $\vec{k}$ ).

King and Rebelo (1989) simulate the transition path of the neoclassical growth model for the case in which the production function is Cobb-Douglas: 


$$
\hat{y}=f(\hat{k})=(\hat{k})^{\alpha}
$$

where $0<\alpha<1$. King and Rebelo use various specifications of the parameters $\alpha, \delta, \rho, \mathrm{g}$, $\mathrm{n}$, and $\theta$. Their baseline case assumes $\alpha=1 / 3, \delta=0.10$ per year, $\rho=0.054$ per year, $\mathrm{g}=0.011$ per year, $\mathrm{n}=0.014$ per year, and $\theta=1$ (log utility). With this specification, the growth rate of $y$ declines monotonically with $\hat{k}$ and, moreover, the saving rate also declines monotonically. King and Rebelo then shift to a low intertemporal elasticity of substitution, $\theta=10$. This change reverses the behavior of the saving rate, which now rises with $\hat{k}$. Nevertheless, the growth rate of y still declines monotonically with $\hat{k}$. Thus, a monotonically declining growth rate of $y$ applies over the range of plausible values for the preference parameter, $\theta$, that matters most for saving behavior. ${ }^{1}$

We can reproduce the main findings of the King-Rebelo simulations from $\log$-linearizations of the dynamic system (equations [3] and [6]) about the steady state. The solution for $\log [\hat{y}(\mathrm{t})]$ in the $\log$-linearized approximation to the model with a Cobb-Douglas technology (equation [8]) is ${ }^{2}$

$$
\log [\hat{y}(t)]=\log [\hat{y}(0)] \cdot e^{-\beta t}+\log \left(\hat{y^{*}}\right) \cdot\left(1-e^{-\beta t}\right)
$$

The growth rate of $y$ still declines monotonically with $\hat{k}$ if $\theta$ is much higher than ten. King and Rebelo report a hump-shaped pattern for the growth rate of $y$ if the utility function is of the Stone-Geary form (which involves a "subsistence" level of per capita consumption), so that the parameter $\theta$ declines with per capita income. That is, the willingness to substitute intertemporally is low ( $\theta$ is high) when per capita income is low. The tendency for $\theta$ to fall over time introduces a force toward increasing per capita growth rates. In equation (6), which determines the growth rate of per capita

consumption, the decline in $\theta$ tends to raise the growth rate, whereas the rise in $\hat{k}$ (and hence, the fall in $\mathrm{f}^{\prime}[\hat{\mathrm{k}}]$ ) tends to reduce the growth rate.

2This solution selects out the stable root, which satisfies the transversality condition. In the log-linearized model, the growth rate of $y$ is always monotonically decreasing if $\hat{y}(0)$ is below the steady-state value, $\hat{y}^{*}$. The results of King and Rebelo (1989) indicate that this property is satisfactory for a wide range of parameter values. See, however, n. 1, which discusses a case in which the growth rate of $y$ is not monotonically decreasing. 
The positive parameter $\beta$, which governs the speed of adjustment to the steady state, depends on the underlying parameters of the model:

$$
2 \beta=\left\{\mathrm{h}^{2}+4\left(\frac{1-\alpha}{\theta}\right)(\rho+\delta+\theta \mathrm{g})\left[\frac{\rho+\delta+\theta \mathrm{g}}{\alpha}-(\mathrm{n}+\delta+\mathrm{g})\right]\right\}^{1 / 2}-\mathrm{h}
$$

where $h=\rho-n-(1-\theta) g>0$.

The average growth rate of per capita output, $y$, over the interval between dates $t_{0}$ and $\mathrm{t}_{0}+\mathrm{T}$ is given by

$$
(1 / T) \cdot \log \left[y\left(t_{0}+T\right) / y\left(t_{0}\right)\right]=g+\frac{\left(1-e^{-\beta T}\right)}{T} \cdot\left[\log \left[\hat{y}^{*} / \hat{y}\left(t_{0}\right)\right]\right]
$$

Therefore, given $\hat{y}^{*}$, the growth rate is higher the lower the value of $\log \left[\hat{y}\left(t_{0}\right)\right]$. The higher $\beta$ the greater the responsiveness of the average growth rate in equation (11) to the gap between $\log \left(\hat{y}^{*}\right)$ and $\log \left[\hat{y}\left(t_{0}\right)\right]$; that is, the more rapid the convergence to the steady state. Equation (10) expresses the dependence of $\beta$ on the underlying parameters, but it is easier to see the nature of these relations numerically.

Because the crucial element for convergence in the neoclassical model is diminishing returns to capital, the extent of this diminishing returns-that is, the size of the capital-share coefficient $\alpha$ in the production function in equation (8) - has a strong effect on $\beta$. Table 1 and Figure 1 show the inverse relation between $\beta$ and $\alpha$, using a set of baseline values for the other parameters ( $\rho=0.05$ per year, $\delta=0.05$ per year, $\mathrm{n}=0.02$ per year, $\mathrm{g}=0.02$ per year, and $\theta=1$ ). Thus, as in King and Rebelo (1989), we assume $\log$ utility $(\theta=1)$ for the baseline case. The value $n=0.02$ per year corresponds to an average of population growth for the United States over the long history. The other baseline parameters come from estimates reported in Jorgenson and Yun (1986, 1990). 
Table 1 shows that for small values of $\alpha$, diminishing returns set in rapidly, $\beta$ is large and convergence is rapid. For example, at $\alpha=0.35$ - a capital share appropriate to a narrow concept of physical capital (see, for example, Maddison [1987]) — the value $\beta=0.126$ per year implies a half-life for the $\log$ of output per effective worker of 5.5 years. That is, half the gap between $\log \left[\hat{\mathrm{y}}\left(\mathrm{t}_{0}\right)\right]$ and $\log \left(\mathrm{y}^{*}\right)$ vanishes in 5.5 years. For $\alpha=0.80$ - which might apply if capital is interpreted broadly to include human capital - the value $\beta=0.026$ per year implies a half-life of 26.9 years. Finally, as $\alpha$ approaches unity, diminishing returns to capital disappear, $\beta$ tends to 0 , and the half-life tends to infinity. This setting without convergence effects is the one assumed in endogenous growth models, such as Romer (1986) and Rebelo (1990), that assume constant returns to a broad concept of reproducible capital.

Figures 2-6 show the effects from variations in the other parameters. In each case, the parameters not being considered are fixed at their baseline values, including $\alpha=0.35$. Figure 2 shows that a higher $\theta$ (reduced willingness to substitute intertemporally) lowers the speed of adjustment. Figure 3 shows that a higher depreciation rate, $\delta$, raises the speed of adjustment. (With full depreciation, convergence to the steady state would be immediate.) Figure 4 indicates that a higher time-preference rate, $\rho$, raises the speed of adjustment. Figures 5 and 6 show that the rate of technological progress, $g$, and the rate of population growth, $n$, have positive but small effects on the speed of adjustment. The results that we report in these figures and in Table 1 correspond well to the non-linear simulations carried out by King and Rebelo (1989) for a more limited range of parameters. ${ }^{3}$

3Equation (10) implies that the effect of $\alpha$ on $\beta$ is unambiguously negative and the effect of $\delta$ is unambiguously positive. Our numerical results indicate that the effects of the other parameters are in the directions shown by the figures as long as the other parameters are restricted to a reasonable range. 
The main implication of the results for the subsequent analysis is that the baseline specification shown in Table 1 generates a short half-life and a rapid speed of adjustment. The speeds of adjustment that we estimate empirically in the next section turn out to be much slower; the values for $\beta$ are in a range from 0.02 to 0.03 per year. The theory conforms to the empirical findings only if we assume parameter values that depart substantially from the baseline case. One possibility is a value of $\alpha$ around 0.8 ; that is, in the range in which the broad nature of capital implies that diminishing returns set in slowly. We can reduce the required value of $\alpha$ to around 0.5 if we assume very high values of $\theta$ (in excess of 10 ) along with a value of $\delta$ close to zero.

\section{Implications of an Open Economy}

Thus far, we have carried out the discussion within the standard setting of a closed economy. This framework is unrealistic for countries, but it is especially implausible for the U.S. states, which we consider below. For our purposes, the important result is that extensions of the neoclassical growth model to allow for features of an open economy tend to speed up the predicted rate of convergence. That is, the predicted convergence coefficient $\beta$ tends to be higher for given values of the parameters that we considered before.

Poorer economies have lower values of $\hat{k}$ and-because of diminishing returns to capital-higher values of the rate of return, $f^{\prime}(\hat{k})$. Therefore, mobility of capital across countries or regions implies that capital will move from rich to poor economies. (Recall the assumption that the production functions, $\mathrm{f}(\cdot)$, are the same in all places.) This process means that poor economies catch up faster than otherwise to rich economies in terms of the values of $\hat{k}$ and $\hat{y}$. It is possible to moderate this prediction in an international context by arguing that the insecurity of property rights deters foreign 
investment. Nevertheless, the predicted convergence with some capital mobility must be greater than that for a group of closed economies.

Diminishing returns to capital imply that wage rates are increasing in $\hat{\mathrm{k}}$. Therefore, the wage rate in rich economies exceeds that in poor economies and international mobility of labor implies that workers will migrate from poor economies to rich ones. As with the movement of capital from rich places to poor places, the shifting of labor from poor to rich tends to raise the level of $\hat{k}$ in poor economies relative to that in rich ones. Therefore, the mobility of labor tends also to speed up the process of convergence in the neoclassical growth model.4

Finally, some models (such as Nelson and Phelps [1966]) bring in the transmission of technology from rich to poor economies. The potential to imitate the leading countries is another reason for poor, follower economies to grow at relatively high rates. That is, it is typically easier to imitate than to innovate. Note also that, unlike the effects from international mobility of capital and labor, this effect from the spread of technology does not depend on diminishing returns to capital.

The closed-economy model implies that an economy's growth rate varies inversely with the level of output per effective worker, $\hat{y}$, relative to the steady-state position, $\hat{y}^{*}$. Thus, if $\hat{y}^{*}$ is constant, the growth rate depends on the level of a country's or region's per capita product, relative only to the steady-state path, which allows for growth at the exogenous rate $g$. In contrast, the open-economy model introduces growth-rate effects that involve the levels of per capita product in relation to the levels in other economies. Thus, the prediction is that a region or country will grow faster if its per

4If we introduce human capital, then the results may change. The conclusions remain the same as long as the people who migrate are those with average or below average quantities of human capital. If people with above-average amounts of human capital are motivated to move from poor to rich economies, then mobility may slow down the process of convergence. See Borjas (1990) for a discussion of the characteristics of immigrants. 
capita product is lower in comparison with that of other economies. Consider as an example a proportionate increase in the levels of capital and output per effective worker in all economies. In the closed-economy model, the per capita growth rate falls in each economy because of diminishing returns to capital. In contrast, the open-economy effects on growth-which involve the mobility of factors and technology-involve inter-country comparisons of rates of return on capital, wage rates, and levels of technical expertise, and do not depend, per se, on the level of world per capita product.

To summarize the main points, in the closed-economy model, the capital-share coefficient, $\alpha$, must be high to match the convergence coefficients that we estimate below. For reasonable values of the other parameters of preferences and technology, the required value for $\alpha$ is in the neighborhood of 0.8 . Open-economy features tend to speed up the convergence process; therefore, open-economy versions of the neoclassical growth model require even higher values of $\alpha$ to fit the observed behavior on convergence.

\section{Two Concepts of Convergence}

Two concepts of convergence appear in discussions of economic growth across countries or regions. In one view (Barro [1984, Ch. 12], Baumol [1986], DeLong [1988], Barro [1991]), convergence applies if a poor country tends to grow faster than a rich one, so that-other things equal-the poor country tends to catch up with the rich one in terms of the level of per capita income or product. The second concept (Easterlin [1960], Borts and Stein [1964, Ch. 2], Streissler [1979], Barro [1984, Ch. 12], Baumol [1986], Dowrick and Nguyen [1989]) concerns cross-sectional dispersion. In this context, convergence occurs if the dispersion-measured say by the standard deviation of the logarithm of per capita income or product across a group of countries or regions-declines over time. Convergence of the first kind (poor economies tending to 
grow faster than rich ones) works toward convergence of the second kind (reduced dispersion of per capita income or product), but is offset by new disturbances that tend to increase dispersion.

Consider a version of equation (11) that applies to discrete periods of unit length (years) and is augmented to include a random disturbance:

$$
\log \left(y_{t}^{i} / y_{t-1}^{i}\right)=a-\left(1-e^{-\beta}\right) \cdot\left[\log \left(y_{t-1}^{i}\right)-g \cdot(t-1)\right]+u_{t}^{i}
$$

where $a=\mathrm{g}+\left(1-\mathrm{e}^{-\beta}\right) \log \left(\mathrm{y}^{*}\right)$, the subscript $\mathrm{t}$ denotes the year, and the superscript $\mathrm{i}$ denotes the country or region. We assume that the random variable $u_{t}^{i}$ has mean zero, variance $\sigma_{u t}^{2}$, and is distributed independently of $\log \left(y_{t-1}^{i}\right), u_{t}^{j}$ for $j \neq i$, and lagged disturbances. We think of the random disturbance as reflecting unexpected changes in production conditions or preferences. We treat the coefficient $a$ as constant; this means, in particular, that the steady-state value, $\left(\hat{y}^{\hat{i}}\right)^{*}$, is the same for all economies. The time trend, $g \cdot(t-1)$, which reflects the exogenous technological progress, is also assumed to be the same for all economies.

Convergence of the first kind applies if $\beta>0$. Because the coefficient on $\log \left(y_{t-1}^{i}\right)$ in equation (12) is $\left(1-\mathrm{e}^{-\beta}\right)$, which is between zero and one, the convergence is not strong enough to eliminate the positive serial correlation in $\log \left(y_{t}^{i}\right)$. Put alternatively - in the absence of random shocks-convergence to the steady state is direct and involves no oscillations.

Let $\sigma_{t}^{2}$ be the cross-economy variance of $\log \left(y_{t}^{i}\right)$ at time $t$. Equation (12) and the assumed properties of $u_{t}^{i}$ imply that $\sigma_{t}^{2}$ evolves over time in accordance with the first-difference equation:

$$
\sigma_{\mathrm{t}}^{2}=\left(\mathrm{e}^{-2 \beta}\right) \cdot \sigma_{\mathrm{t}-1}^{2}+\sigma_{\mathrm{ut}}^{2}
$$


In our empirical discussion in a following section, we assume that the cross section is large enough so that the sample variance of $\log \left(y_{t}^{i}\right)$ corresponds to the population variance, $\sigma_{\mathrm{t}}^{2}$.

If $\sigma_{\mathrm{ut}}^{2}$ equals the constant $\sigma_{\mathrm{u}}^{2}$ and $\sigma_{0}^{2}$ is the variance of $\log \left(\mathrm{y}_{\mathrm{t}_{0}}^{\mathrm{i}}\right)$, then the solution of the first-difference equation (13) is

$$
\sigma_{\mathrm{t}}^{2}=\frac{\sigma_{\mathrm{u}}^{2}}{1-\mathrm{e}^{-2 \beta}}+\left(\sigma_{0}^{2}-\frac{\sigma_{\mathrm{u}}^{2}}{1-\mathrm{e}^{-2 \beta}}\right) \cdot \mathrm{e}^{-2 \beta \mathrm{t}}
$$

Equation (14) implies that $\sigma_{\mathrm{t}}^{2}$ approaches the steady-state value, $\sigma^{2}=\sigma_{\mathrm{u}}^{2} /\left(1-\mathrm{e}^{-2 \beta}\right)$, which rises with $\sigma_{\mathrm{u}}^{2}$ but declines with the convergence coefficient, $\beta$. Over time, $\sigma_{\mathrm{t}}^{2}$ falls (or rises) if the initial value $\sigma_{0}^{2}$ is greater than (or less than) the steady-state value, $\sigma^{2}$. Thus, a positive coefficient $\beta$ ( $\beta$-type convergence) does not require a falling $\sigma_{\mathrm{t}}^{2}$ ( $\sigma$-type convergence). To put it another way, $\beta$-convergence is necessary but not sufficient for $\sigma$-convergence.

Figure 7 shows the time pattern of $\sigma_{\mathrm{t}}^{2}$ with $\sigma_{0}^{2}$ above or below $\sigma^{2}$. The convergence coefficient used, $\beta=0.03$ per year, corresponds to estimates for the United States in the next section. With $\beta=0.03$ per year, it takes about 12 years to eliminate $50 \%$ of the initial gap between $\sigma_{0}^{2}$ and $\sigma^{2}$, and about 23 years to eliminate $75 \%$ of the gap.

The cross-sectional dispersion of $\log \left(y_{t}^{i}\right)$ is sensitive to shocks that have a common influence on sub-groups of countries or regions. (These kinds of disturbances violate the condition that $u_{t}^{i}$ in equation (12) is independent of $u_{t}^{j}$ for $j \neq i$.) Examples are shocks that generate changes in the relative prices of agricultural commodities or oil. These kinds of changes are favorable for some countries or regions and unfavorable for others. For the United States, an important example from the earlier history is the Civil War. 
This shock had a strong adverse effect on the incomes of southern states relative to the incomes of northern states.

Formally, let $S_{t}$ be a random variable that represents an economy-wide disturbance for period $t$. For example, $S_{t}$ could reflect the relative price of oil as determined in world markets. Then equation (12) could be modified to

$$
\log \left(y_{t}^{i} / y_{t-1}^{i}\right)=a-\left(1-e^{-\beta}\right) \cdot\left[\log \left(y_{t-1}^{i}\right)-g t\right]+\phi^{i} \cdot S_{t}+u_{t}^{i}
$$

where $\phi^{\mathrm{i}}$ measures the effect of the aggregate disturbance on the growth rate in country or region $i$. If a positive value of $S_{t}$ signifies an increase in the relative price of oil, then $\phi^{\mathrm{i}}$ would be positive for countries or regions that produce a lot of oil. The coefficient $\phi^{\mathrm{i}}$ would tend to be negative for economies that produce goods, such as automobiles, that use oil as an input. We think of the coefficients $\phi^{i}$ as distributed cross sectionally with mean $\bar{\phi}$ and variance $\sigma_{\phi}^{2}$.

Equation (15) implies

$$
\sigma_{\mathrm{t}}^{2}=\left(\mathrm{e}^{-2 \beta}\right) \cdot \sigma_{\mathrm{t}-1}^{2}+\sigma_{\mathrm{u}}^{2}+\mathrm{S}_{\mathrm{t}}^{2} \cdot \sigma_{\phi}^{2}+2 \mathrm{~S}_{\mathrm{t}} \cdot\left(\mathrm{e}^{-\beta}\right) \cdot \operatorname{COV}\left[\log \left(\mathrm{y}_{\mathrm{t}-1}^{\mathrm{i}}\right), \phi^{\mathrm{i}}\right]
$$

where the variances and covariance are conditioned on the current and past realizations of the aggregate shocks, $S_{t}, S_{t-1}, \ldots$ If $\operatorname{COV}\left[\log \left(y_{t-1}^{i}\right), \phi^{i}\right]$ equals zero, then equation (16) corresponds to equation (13), except that realizations of the shock $S_{t}$ effectively move $\sigma_{\mathrm{ut}}^{2}$ around over time. A temporarily large value of $\mathrm{S}_{\mathrm{t}}$ (due, for example, to an oil or agricultural shock or a war) raises $\sigma_{\mathrm{t}}^{2}$ above the long-run value $\sigma^{2}$ that corresponds to a normal (smaller) value of $S_{t}$. Therefore, in the absence of a new shock to $S_{t}, \sigma_{t}^{2}$ returns gradually toward $\sigma^{2}$ as shown in Figure 7 . 
It also follows when $\log \left(\mathrm{y}_{\mathrm{t}-1}^{\mathrm{i}}\right)$ and $\phi^{\mathrm{i}}$ are uncorrelated that estimates of the coefficient $\beta$ in equation (15) would not be systematically related to the realizations of $S_{t}$. That is, the composite error term, $\phi^{i} \cdot S_{t}+u_{t}^{i}$, would be uncorrelated with the regressor, $\log \left(\mathrm{y}_{\mathrm{t}-1}^{\mathrm{i}}\right)$.

Suppose, alternatively, that $\operatorname{COV}\left[\log \left(y_{t-1}^{i}\right), \phi^{i}\right]>0$. That is, if a positive $S_{t}$ represents an increase in the relative price of oil, then countries or regions that produce a lot of oil $\left(\phi^{\mathrm{i}}>\bar{\phi}\right)$ have above average per capita product in period $t-1$. In this case, the derivative of the covariance term in equation (16) with respect to $S_{t}$ is positive. Therefore, the derivative of $\sigma_{t}^{2}$ with respect to $S_{t}$ is positive if $S_{t}>0$, but may be positive or negative if $\mathrm{S}_{\mathrm{t}}<0$. If $\log \left(\mathrm{y}_{\mathrm{t}-1}^{\mathrm{i}}\right)$ and $\phi^{\mathrm{i}}$ were perfectly correlated-so that $\operatorname{COV}\left[\log \left(\mathrm{y}_{\mathrm{t}-1}^{\mathrm{i}}\right), \phi^{\mathrm{i}}\right]=\sigma_{\mathrm{t}-1} \cdot \sigma_{\phi}-\sigma_{\mathrm{t}}^{2}$ would be monotonically increasing in $\mathrm{S}_{\mathrm{t}}$. For the oil example (in which oil-producing economies have above-average per capita product), the results imply that an increase in the relative price of oil has a positive effect on the cross-sectional dispersion of per capita product. A decrease in the relative price of oil may lower this dispersion, and surely lowers it if the correlation between $\log \left(y_{t-1}^{i}\right)$ and $\phi^{\mathrm{i}}$ is unity.

If $\log \left(y_{t}^{i}\right)$ and $\phi^{i}$ are positively correlated, then the coefficient estimated by OLS on $\log \left(y_{t-1}^{i}\right)$ in equation (15) would be positively or negatively biased as $\mathrm{S}_{t}$ is positive or negative. As an example, if oil producers have relatively high per capita product, then OLS procedures tend to underestimate $\beta$-convergence for a period in which the oil price rises $\left(S_{t}>0\right)$ and vice versa. In the empirical analysis in a later section, we hold constant proxies for $S_{t}$ as an attempt to obtain consistent estimates of the convergence coefficient $\beta$.

\section{The Data for the U.S. States}

We have two measures of per capita income or product across the U.S. states. The 
first measure is per capita, nominal personal income. The U.S. Commerce Department has published annual data on personal income for the 48 continental states since 1929 (see Bureau of Economic Analysis [1986]). We use the figures that exclude transfer payments. Easterlin $(1957,1960)$ provides estimates of state personal income for 1840 (29 states or territories), 1880 (47 states or territories), 1900 (48 states or territories), and 1920 (48 states). . These data also exclude transfer payments.

We do not have measures of price levels or price indexes for individual states. Therefore, we deflate the nominal values for each state by a national price index for the year. From 1929 to 1988 we use the U.S. deflator for national income. For the earlier years, we use wholesale price indexes for all commodities. Given that we use the same price deflator for each state in a single year, the particular deflator that we use affects only the constant terms in the subsequent analysis. The use of the same deflator for each state introduces two types of potential measurement error. First, if relative purchasing-power parity does not hold across the states, then the growth rates of real per capita income are mismeasured. Second, if absolute purchasing power parity does not hold, then the levels of real per capita income are mismeasured.

The second type of data is per capita, nominal gross state product (GSP), which is available annually from 1963 to 1986 (see Renshaw, Trott and Friedenberg [1988]). This variable, which is analogous to gross domestic product, measures production within each state. We deflate the nominal figures by the aggregate gross state product deflator for each year. (This deflator is close to that for U.S. gross domestic product.)

The main differences between state personal income and gross state product involve capital income. Personal income includes corporate net income only when individuals receive payment as dividends, whereas GSP includes corporate profits and depreciation. (Neither concept includes capital gains.) In addition, GSP attributes capital income to the state in which the business activity occurs, whereas personal 
income attributes it to the state of the asset holder. Some of these locational considerations apply also to labor income, although - except for a few cities-the location of a business and the residence of the workers are typically in the same state.

\section{Evidence on $\underline{\beta-C o n v e r g e n c e ~ f o r ~ t h e ~ U . S . ~ S t a t e s ~}$}

We assume in this section that the neoclassical growth model described before applies to each of the U.S. states as separate economies. (Thus, we assume that the main effect from openness is that the convergence coefficient, $\beta$, is higher than otherwise.) We have data on real per capita income or product, $y_{t}^{i}$, for a cross section of the U.S. states, $i=1, \ldots, N$. Assume for the moment that we use data only at two points in time: $t_{0}$ and $t_{0}+T$. Then equation (12) implies that the average growth rate over the interval from $\mathrm{t}_{0}$ to $\mathrm{t}_{0}+\mathrm{T}$ is given by

(17) $(1 / \mathrm{T}) \cdot \log \left(\mathrm{y}_{\mathrm{t}_{0}+\mathrm{T}}^{\mathrm{i}} / \mathrm{y}_{\mathrm{t}_{0}}^{\mathrm{i}}\right)=a-\left[\left(1-\mathrm{e}^{-\beta \mathrm{T}}\right) / \mathrm{T}\right] \cdot \log \left(\mathrm{y}_{\mathrm{t}_{0}}^{\mathrm{i}}\right)+\mathrm{u}_{\mathrm{t}_{0}, \mathrm{t}_{0}+\mathrm{T}}^{\mathrm{i}}$

where $u_{t_{0}, t_{0}}^{i}+T$ represents the average of the error terms, $u_{t}^{i}$, between dates $t_{0}$ and $\mathrm{t}_{0}+\mathrm{T}$. The constant term, $a=\mathrm{g}+\left[\left(1-\mathrm{e}^{-\beta \Gamma}\right) / \mathrm{T}\right] \cdot\left[\log \left(\hat{\mathrm{y}}^{*}\right)+\mathrm{gt}_{0}\right]$, incorporates the constant and the time trend from equation (12) because the trend, gt, is the same for all i. The coefficient $a$ would shift with a change in the starting date for the sample, $\mathrm{t}_{0}$.

Note that the coefficient on $\log \left(y_{t_{0}}^{i}\right)$ is $\left(1-e^{-\beta T}\right) / T$, which declines with the length of the interval, $\mathrm{T}$, for a given $\beta$. Intuitively, as we consider longer intervals, the effect of the initial position on the average growth rate must get smaller; in the limit as $\mathrm{T}$ tends to infinity, the coefficient tends to zero. Our non-linear estimates of $\beta$ take account of the associated value of $\mathrm{T}$. Therefore, we expect to obtain similar estimates of $\beta$ regardless of the length of the interval. 
Table 2 shows non-linear least-squares regressions in the form of equation (17) for 47 or 48 U.S. states or territories and for various time periods. Aside from $\log \left(y_{t_{0}}^{i}\right)$, each regression includes a constant and three regional dummy variables: south, midwest, west. (To save space, the estimated coefficients for the constant and the regional dummies are not shown in the table.) Because the regional dummies are held constant, the effect of initial per capita income does not reflect purely regional differences, such as the southern states catching up with the northern states.

For the longest interval, 1880-1988, the estimated convergence coefficient shown in line 1 of Table 2 is $\hat{\beta}=.0175$ (s.e. $=.0046$ ). Figure 8 shows the dramatic inverse relation between the average growth rate from 1880 to $1988, \Delta y_{1880,1988}$, and $\log \left(\mathrm{y}_{1880}\right)$ : the simple correlation is -0.93 . Figure 9 and line 2 of Table 2 show that the results are similar for the interval 1930-1988: $\dot{\beta}=.0143$ (.0028).

The full time series for $y_{t}^{i}(1880,1900,1920$, and annually from 1929) potentially provides more information about the coefficient $\beta$. For a smaller value of $\mathrm{T}$, however, the error term in equation (17), $\mathrm{u}_{\mathrm{t}_{0}, \mathrm{t}_{0}+\mathrm{T}}^{\mathrm{i}}$, represents an average of shocks over a shorter interval. Therefore, the estimates become more sensitive to the specification of the error process. In particular, with serial persistence in the error term $u_{t}^{i}$, the correlation between $u_{t_{0}, t_{0}}^{i}+T$ and $\log \left(y_{t_{0}}^{i}\right)$ is likely to be negligible for large $T$ but substantial for small $\mathrm{T}$.

Table 2, lines 3-11, shows estimates of $\beta$ for nine sub-periods of the overall sample: 1880-1900, 1900-1920, ten-year intervals from 1920 to 1980, and 1980-1988. Each regression includes a constant and the three regional dummies. The results show values of $\hat{\beta}$ that range from -.0122 (.0074) for $1920-1930$ to .0373 (.0053) for $1940-1950$.

If all nine sub-periods are restricted to have a single value for $\beta$, then the resulting joint estimate, shown on line 12 , is $\hat{\beta}=.0189$ (.0019). This joint estimation allows each 
sub-period to have individual coefficients for the constant and the regional dummies. ${ }^{5}$

This jointly estimated value of $\hat{\beta}$ is, in fact, close to the value, .0175, that was estimated for the single interval 1880-1988. But, as would be expected, the standard error from the joint estimation, .0019, is a good deal smaller than that, .0046, found for the single interval.

The problem with the joint estimate is that the data reject the hypothesis that the coefficient $\beta$ is the same for the nine sub-periods. The likelihood-ratio statistic for this hypothesis, 32.1 , is well above the $5 \%$ critical value from the $\chi^{2}$ distribution ( 8 d.f.) of 15.5 .

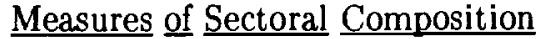

The unstable pattern of $\hat{\beta}$ coefficients across sub-periods can reflect aggregate disturbances that have differential effects on state incomes, as represented by the term $\phi^{\mathrm{i}} \mathrm{S}_{\mathrm{t}}$ in equation (15). For example, during the $1920 \mathrm{~s}$, the ratio of the wholesale price of agricultural commodities to the CPI fell by $29 \%$. The agricultural states also had below-average per capita personal income in 1920; the correlation of $\log \left(\mathrm{y}_{1920}\right)$ with the share of national income originating in agriculture in 1920 was -0.67 . Thus, the estimated coefficient $\hat{\beta}=-.0122$ for the $1920-1930$ period in Table 2 may reflect the tendency of the poorer states to be agricultural and therefore to experience relatively low growth in this particular decade.

To hold constant this type of effect, we construct a variable that measures the sectoral composition of income in each state. For the sub-periods that begin since 1930 , we have a breakdown of the sources of labor income (including income from self

5It would be possible to restrict the constants if it were maintained that each state experienced exogenous technological progress at the constant rate g. We could then use the whole sample to estimate a single constant and the value of $g$. We have not imposed these restrictions because we have no reason to think that the rate of technological change would be the same over all time periods. 
employment) into nine categories: agriculture, mining, construction, total manufacturing, transportation \& public utilities, wholesale \& retail trade, finance-insurance-real estate, services, and government \& government enterprises. For each sub-period, we construct a sectoral-composition variable for state i:

$$
S^{i}=\sum_{j=1}^{9} w_{j 0}^{i} \cdot \Delta y_{j}
$$

where $j$ indexes the sectors for the generation of income, $w_{j 0}^{i}$ is the share of personal income in state $i$ that is generated at the start of the sub-period by sector $j$, and $\Delta y_{j}$ is the growth rate for the sub-period of U.S. personal income that originates in sector $\mathrm{j}$. For example, if U.S. income in agriculture grows at a low rate in a particular sub-period, then $S^{i}$ is especially low for agricultural states in that sub-period.

For the sub-periods that begin before 1930, we lack detailed data on the sectoral composition of personal income. We do have data by state on the fraction of national income originating in agriculture. For these sub-periods, we use this fraction as a measure of $S^{i}$. Note that the different methods of construction and the differing behavior of agricultural relative prices mean that the coefficients of the variable $S^{i}$ will differ from one sub-period to another. Therefore, we estimate a separate coefficient on $\mathrm{S}^{\mathrm{i}}$ for each sub-period.

Lines 13-21 in Table 2 add the variable $S^{i}$ to the growth-rate regressions for each sub-period. As before, these regressions include $\log \left(y_{t_{0}}^{i}\right)$, a constant, and three regional dummies. Not surprisingly, the estimated coefficients on the variable $S^{\mathrm{i}}$ for the post-1930 sub-periods are typically positive. That is, states in which income originates predominantly in sectors that do well at the national level tend to have higher per capita growth rates. (The estimated coefficient for the 1940-1950 sub-period is 
negative, -0.40 , s.e. $=0.57$, but not significantly so.) For the sub-periods that begin before 1930, the negative estimated coefficient on $S^{i}$ signifies that, holding constant initial per capita income and region, agricultural states have lower per capita growth rates. This pattern is especially clear during the agricultural price collapse in the 1920-1930 sub-period: the estimated coefficient on $\mathrm{S}^{\mathrm{i}}$ is -.0936 (.0175).

For our purposes, the principal finding from the addition of the $S^{i}$ variables is that the estimated $\beta$-coefficients become much more stable across sub-periods. The range is now $.0139(.0076)$ for $1970-1980$ to $.0362(.0055)$ for 1940-1950. Line 22 shows that the jointly estimated coefficient for the nine sub-periods is .0249 (.0021). (This joint estimation allows each sub-period to have individual coefficients for $S^{\mathrm{i}}$, as well as for the constant and the regional dummies.) The likelihood-ratio statistic for the equality of $\beta$-coefficients across the nine sub-periods is now 13.9 , compared to the $5 \%$ critical value of 15.5. Thus, if we hold constant the measures of sectoral composition, we no longer reject the hypothesis of a single $\beta$ coefficient at the $5 \%$ level. Note also that the estimated value, $\hat{\beta}=.0249$, is higher than that estimated on line $12, .0189$, when the variable $S^{\mathrm{i}}$ was omitted.

The regression on line 23 of Table 2 includes the sectoral-composition variable over the full sample 1930-1988. The estimated coefficient is now $\dot{\beta}=.0207$ (.0049), compared to $.0143(.0028)$ when the variable $\mathrm{S}^{\mathrm{i}}$ was omitted on line 2 . (We cannot include a single $S^{\mathrm{i}}$ variable over the sample 1880-1988 because of missing data on sectoral composition before 1929.)

The final result from Table 2 is a regression with the 29 available observations from 1840 to $18800^{\circ}$ This regression includes a constant and two regional dummies (no

-According to Easterlin (1960, pp. 124 ff.), the data for 1840 do not cover income originating in wholesale \& retail trade, finance-insurance-real estate, government, or most other services. The figures that we use for 1880 in the 1840-1880 regressions are comparable in coverage to those for 1840 . This more limited coverage for 1880 comprises about half the income included in the measure that we used previously. In 
western states are in the sample). We exclude the variable $S^{i}$ because the data are unavailable. The estimate on line 24 is $\hat{\beta}=.0254$ (.0067), which accords with the estimate of $.0249(.0021)$ for the sub-periods that begin after 1880 (line 22).

Figure 10 plots the per capita growth rate, $\Delta \mathrm{y}_{1840,1880}$, against $\log \left(\mathrm{y}_{1840}\right)$. A remarkable aspect of the plot is the separation of the southern and non-southern states because of the Civil War. In 1840, the southern and non-southern states differed little in terms of average per capita income; the southern average was $94 \%$ of the non-southern. But in 1880 a wide gap had appeared and the southern average was only $50 \%$ of the non-southern. The figure shows, however, that $\beta$-convergence applies to the southern and non-southern states as separate groups. That is, holding constant the regional dummies (which effectively holds constant the impact of the Civil War), there is a strong negative correlation between the per capita growth rate and the initial level of per capita income.

As with the agricultural price collapse in the 1920s, the Civil War represents a disturbance that affects states differentially. But, unlike the shock to agriculture in the 1920s, the effect of the Civil War on state per capita income has little correlation with the initial level of per capita income. That is, the southern states-which were adversely affected by the Civil War-did not have initial levels of per capita income that were substantially below average. For this reason, we do not get a very different point estimate of $\beta$ for the 1840-1880 sub-period if we eliminate the variables-in this case the regional dummies - that hold constant the Civil War disturbance. Without regional dummies, the estimate is $\hat{\beta}=.0203(.0126)$. On the other hand, the $\mathrm{R}^{2}$ of the regression falls from 0.91 in line 24 of Table 2 to 0.19 ; that is, the regional dummies have a lot of explanatory power in this period!

any event, the limited figures for 1840 are not comparable to the data for years after 1880. 


\section{$\underline{\text { Results }} \underline{\text { with }} \underline{\text { Gross }} \underline{\text { State }} \underline{\text { Product }}$}

Table 3 and Figure 11 deal with the growth of per capita gross state product (GSP) for 48 states over the period 1963-1986. Over the full sample, the estimated convergence coefficient on line 1 of the table is $\hat{\beta}=.0180(.0059)$. This regression includes a constant and the three regional dummy variables, but no measures of sectoral composition. The regressions over sub-periods (1963-1969, 1969-1975, 1975-1981, 1981-1986 on lines 2-5) show marked instability in $\hat{\beta}$ : the range is from -.0285 in 1975-1981 to 1130 in 1981-1986. The joint estimate of $\beta$ from the four sub-periods (line 6$)$ is $.0211(.0053)$, but the test of equality of coefficients is rejected (likelihood-ratio statistic $=31.2$, compared to the $5 \%$ critical value of 7.8 ).

We again add a measure of sectoral composition, $\mathrm{S}^{\mathrm{i}}$, which is analogous to that defined in equation (18). However, the data allow us to disaggregate into 54 sectors for the origination of GSP. Lines $7-11$ in Table 3 show that the $\dot{\beta}$ coefficients are similar across the sub-periods when the variable $S^{i}$ is held constant. The joint estimate (line $11)$ is $\hat{\beta}=.0216(.0042)$ and the hypothesis of stability across the four sub-periods is accepted (likelihood-ratio statistic $=1.7$, compared to the $5 \%$ critical value of 7.8 ).

The joint estimate of $\beta$ from the GSP regressions is similar to that obtained with personal income. The joint estimate for personal income in Table 2 , line 22 is .0249 (.0021), which is slightly higher than that, .0216, found with GSP. However, if the estimation for personal income is limited to a similar time span to that covered by GSP - that is, the three sub-periods, 1960-1970, 1970-1980, and 1980-1988-the joint estimate is $\hat{\beta}=.0181(.0040)$, which is slightly less than that obtained with GSP. The main conclusion is that the estimated convergence coefficients are similar whether we use personal income or gross state product.

Some of the instability in the $\hat{\beta}$ coefficients with the GSP data relate to the movements in oil prices. Oil prices and hence, the incomes of oil states rose 
substantially during the sub-period 1975-1981. Moreover, the oil states were already relatively high in per capita GSP by 1975: the correlation of per capita GSP with the share of GSP originating in crude oil and natural gas was 0.4 . The tendency of the rich oil states to grow at a relatively high rate upsets the usual convergence pattern and thereby leads to the negative value for $\hat{\beta},-.0285$, shown for 1975-1981 in line 4 of Table 2.7 But, when sectoral composition is held constant in line 9 , the value of $\hat{\beta}$ for 1975-1981 is similar to that found in other periods.

For the 1981-1986 period, the key elements are the sharp decline in oil prices and the high correlation, 0.7 , between per capita GSP and the share of GSP originating in oil and natural gas in 1981. Accordingly, the tendency for oil states to do badly in 1981-1986 leads to an exaggerated convergence coefficient, $\hat{\beta}=.1130$, in line 5.8 Again, the inclusion of the $S^{\mathrm{i}}$ variable in line 10 leads to a normal value for $\hat{\beta}$.

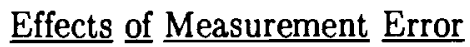

The types of regressions that we have been running can exaggerate the estimated convergence coefficient, $\hat{\beta}$, if real income or product is measured with error. Aside from the usual measurement problems, one reason to expect errors is that we divide all nominal values in each year by a common price index.

Equation (17) can be rewritten as

$$
(1 / \mathrm{T}) \cdot \log \left(\mathrm{y}_{\mathrm{t}_{0}+\mathrm{T}}^{\mathrm{i}}\right)^{*}=a+\left(\mathrm{e}^{-\beta \mathrm{T}} / \mathrm{T}\right) \cdot \log \left(\mathrm{y}_{\mathrm{t}_{0}}^{\mathrm{i}}\right)^{*}+\mathrm{u}_{\mathrm{t}_{0}, \mathrm{t}_{0}+\mathrm{T}}^{\mathrm{i}}
$$

7This argument does not apply to the sub-period 1969-1975 (lines 3 and 8 of Table 2). Although the oil price rose substantially over this period, the oil states did not have especially high values of per capita GSP in 1969.

${ }^{8}$ The results for personal income over the period 1980-1988 (Table 2, lines 11 and 21) do not show the same pattern. The main difference seems to be that the correlation in 1980 of the logarithm of per capita personal income with the share of income originating in oil and natural gas is close to zero. 
where the asterisks indicate values measured without error. Assume that the observed value at date $t, \log \left(y_{t}^{i}\right)$, differs from $\log \left(y_{t}^{i}\right)^{*}$ by a random measurement error:

$$
\log \left(y_{t}^{i}\right)=\log \left(y_{t}^{i}\right)^{*}+\eta_{t}
$$

For purely temporary measurement error, $\eta_{\mathrm{t}}$ would be white noise. Then, as is well known, the measurement error in $\log \left(\mathrm{y}_{\mathrm{t}_{0}}^{\mathrm{i}}\right)$ implied by equation (20) leads to a bias toward zero in OLS estimation of the coefficient, $\mathrm{e}^{-\beta \mathrm{T}} / \mathrm{T}$, in equation (19). The extent of the bias is increasing in the ratio of the variance of the noise, $\eta_{\mathrm{t}}$, to the variance of the signal, $\log \left(\mathrm{y}_{\mathrm{t}}^{\mathrm{i}}\right)^{*}$. Because the term, $\mathrm{e}^{-\beta \mathrm{T}} / \mathrm{T}$, in equation (19) is decreasing in $\beta$, the non-linear estimate $\hat{\beta}$ provides a corresponding overestimate of $\beta$ in large samples.

We can obtain a bound for the inconsistency induced by temporary measurement error. Equation (12) implies that the growth rate of income between any two future dates, $\mathrm{t}_{0}+\tau$ and $\mathrm{t}_{0}+\mathrm{T}$, is given by

(21) $[1 /(\mathrm{T}-\tau)] \cdot \log \left(\mathrm{y}_{\mathrm{t}_{0}+\mathrm{T}}^{\mathrm{i}} / \mathrm{y}_{\mathrm{t}_{0}+\tau}^{\mathrm{i}}\right)^{*}=a-\left[\left(\mathrm{e}^{-\beta \tau}-\mathrm{e}^{-\beta \mathrm{T}}\right) /(\mathrm{T}-\tau)\right] \cdot \log \left(\mathrm{y}_{\mathrm{t}_{0}}^{\mathrm{i}}\right)^{*}+\mathrm{u}_{\mathrm{t}_{0}+\tau, \mathrm{t}_{0}+\mathrm{T}}^{\mathrm{i}}$

where $\mathrm{T}>\tau>0$ and $\mathrm{u}_{\mathrm{t}_{0}}^{\mathrm{i}}+\tau, \mathrm{t}_{0}+\mathrm{T}$ is the average of the error terms between dates $\mathrm{t}_{0}+\tau$ and $t_{0}+T$. Equation (21) relates the growth rate from $t_{0}+\tau$ to $t_{0}+T$ to the level of per capita income at an earlier time, date $t_{0}$. Note that equation (17) corresponds to the special case in which $\tau=0$.

We assume that the measurement error, $\eta_{\mathrm{t}_{0}}$, is independent of $\eta_{\mathrm{t}_{0}+\mathrm{t}}$ for $\mathrm{t} \geq \tau$. This condition holds for all $\tau>0$ if $\eta_{\mathrm{t}}$ is white noise, but also applies for large enough $\tau$ to measurement error with some persistence over time. We also assume that $\eta_{\mathrm{t}_{0}}$ is 
independent of $u_{t_{0}}^{i}+\tau, t_{0}+T$. In this case, OLS estimation of equation (21) leads to an underestimate of the magnitude of the coefficient, $\left[\left(\mathrm{e}^{-\beta \tau}-\mathrm{e}^{-\beta \mathrm{T}}\right) /(\mathrm{T}-\tau)\right]$. We can show that this term is increasing in $\beta$ if $\beta<[\log (T / \tau)] /(T-\tau)$. In practice, we use the values $\tau=10$ years and $\mathrm{T}=20$ years or $\tau=5$ years and $\mathrm{T}=10$ years. For the first pair of values, the term $\left[\left(\mathrm{e}^{-\beta \tau}-\mathrm{e}^{-\beta \mathrm{T}}\right) /(\mathrm{T}-\tau)\right]$ is increasing in $\beta$ if $\beta<0.07$ per year; for the second pair, the term is increasing in $\beta$ if $\beta<0.14$ per year. Therefore, for these ranges of $\beta$ and in large samples, the underestimate of the coefficient on $\log \left(\mathrm{y}_{\mathrm{t}_{0}}^{\mathrm{i}}\right)$ in equation (21) corresponds to an underestimate of $\beta$. Because this bias in $\hat{\beta}$ is opposite in direction to that found for equation (19), we can use regressions in the form of equation (21) to bound the size of the bias.

Consider the regressions for personal income in which each sub-period has individual coefficients for the constant, three regional dummies, and the sectoral-composition variable, $S^{i}$. If we use only the five sub-periods from 1930-1940 to $1970-1980$, then the joint estimate $\hat{\beta}$ in the form of equation (17) is $.0244(.0025)$, which is close to the value for nine sub-periods from 1880 to 1988 shown in Table 2, line 22. The comparable result in the form of equation (21) with $\tau=10$ years and $\mathrm{T}=20$ years is $\hat{\beta}=.0278(.0049)$. Although the asymptotic biases induced by temporary measurement error would be positive in the first case and negative in the second, the result for $\hat{\beta}$ turns out to be higher in the second case. But the main finding is that the values of $\hat{\beta}$ are similar in the two cases. Our inference is that temporary measurement error does not have much influence on the results.

For gross state product, we used the three sub-periods, 1970-1975, 1975-1980, and $1980-1985$. The joint estimate $\hat{\beta}$ in the form of equation (17) is $.0280(.0058)$, somewhat higher than that, .0216 (.0042), shown for four sub-periods from 1963 to 1986 in Table 3 , line 11 . Using $\tau=5$ years and $\mathrm{T}=10$ years, joint estimation of equation (21) 
over the three sub-periods from 1970 to 1985 leads to $\hat{\beta}=.0366$ (.0091). Again, contrary to expectations, the estimated value in the second case exceeds that in the first case. But the main inference is that the results are similar and, hence, that temporary measurement error is unlikely to be important.

\section{Migration of Labor}

As mentioned before, one way for the per capita product of poor and rich economies to converge is for workers to move from poor places to rich places. Sala $i$ Martin (1990, Table 5.2) relates net migration for the U.S. states to initial values of per capita personal income over sub-periods of the interval from 1900 to 1987. He confirms that net in-migration is positively related to initial per capita income. But he also notes (Table 5.4) that the estimated convergence coefficients, $\hat{\beta}$, are little affected by the inclusion of net migration as an additional explanatory variable in a growth-rate equation. In other words, his finding is that net migration of population plays a minor role in the convergence results.

\section{Sectoral Productivity}

We can disaggregate total output (say, gross state product) into value added by various sectors of production. Then we can break down the changes in overall productivity — say output per worker-into changes in the sectoral composition of output and changes in productivity within each sector. Sala i Martin (1990, Table 3.9) shows that the $\beta$-convergence for gross state product over the period 1963 to 1986 involves primarily the convergence of productivity within non-agricultural sectors. (He lacked comparable data on agricultural productivity by state.) The convergence effect shows up most strongly for manufacturing, but significant effects show up also for six other sectors: construction, mining, services, transportation, wholesale and retail trade, 
and finance-insurance-real estate. Thus, the poorer states tend to grow faster not only in terms of overall output per person, but also in terms of labor productivity within various sectors of production.

\section{Analysis of $\underline{\sigma-C o n v e r g e n c e}$}

Column 1 of Table 4 shows the behavior from 1840 to 1988 of $\sigma_{t}$, the standard deviation of the logarithm of per capita personal income, $\log \left(y_{t}^{i}\right)$. For the 29 states or territories with data in $1840, \sigma_{\mathrm{t}}$ rose from 0.30 in 1840 to 0.37 in 1880. This increase reflects the shock from the Civil War. As indicated in Figure 10, the war generated a large separation between the southern and non-southern states. If we compute $\sigma_{\mathrm{t}}$ separately for the southern and non-southern regions, then we find a substantial decline in each case: from 0.26 to 0.12 for the south and from 0.32 to 0.18 for the north. Thus, the Civil War appears as a major disturbance (like $\phi^{\mathrm{i}} \mathrm{S}_{\mathrm{t}}$ in equation [15]) that is superimposed on a pattern of declining cross-sectional variance of personal income.

Column 1 of Table 4 shows that $\sigma_{\mathrm{t}}$ for 47 states or territories was 0.54 in 1880. The coverage for income that underlies this figure is much broader than that used above to compute $\sigma_{\mathrm{t}}$ for 29 states or territories in 1880 (see n. 6). Thus, the figures shown for 47 or 48 states or territories for 1880 and later are not comparable to those shown for 29 states or territories for 1840 and 1880 . (The shift in the level of $\sigma_{t}$ for 1880 is not due primarily to the change from 29 to 47 observations.) The value of $\sigma_{\mathrm{t}}$ falls from 0.54 in 1880 to 0.46 in 1900 and 0.32 in 1920 . This decline reflects the $\sigma$-convergence captured by equation (14). If $\sigma_{1880}$ is above the steady-state value, $\sigma$, and if major new shocks that affect the states differentially do not occur, then $\sigma_{\mathrm{t}}$ declines toward $\sigma$ over time.

The increase in $\sigma_{\mathrm{t}}$ to the value 0.40 in 1930 likely reflects the impact of the agricultural price collapse, which has already been discussed. The effect on $\sigma_{t}$ is particularly strong because the adverse shock fell most heavily on states in which per 
capita income was already below average. That is, in terms of equation (16), the covariance between initial per capita income and the impact of the agricultural shock is positive.

After remaining roughly stable during the $1930 \mathrm{~s}, \sigma_{\mathrm{t}}$ falls dramatically during World War II from 0.35 in 1940 to 0.24 in 1945. Then, after changing little until 1950, $\sigma_{\mathrm{t}}$ falls gradually to 0.15 in 1975 and subsequently rises to 0.19 in 1988 . The rise in $\sigma_{\mathrm{t}}$ since the mid 1970s may relate to the fluctuations in the relative prices of oil and other commodities. However, the timing of the interaction between oil shocks and $\sigma_{t}$ for personal income is unclear. One consideration is that, unlike the agricultural price shock in the 1920s, the share of income originating in oil and natural gas is not highly correlated with per capita personal income. If the oil states had above-average per capita income, then the effects of oil shocks on $\sigma_{t}$ would be more pronounced. (Since the mid 1970s, the oil states have above-average values of per capita gross state product, but not per capita personal income.)

Column 2 of Table 4 shows $\sigma_{\mathrm{t}}$ from 1963 to 1986 based on per capita GSP. The gradual decline in $\sigma_{t}$ from 1963 to 1975 is similar to the pattern found for personal income. The rise in $\sigma_{\mathrm{t}}$ from 0.14 in 1975 to 0.17 in 1980 likely reflects the increase in the relative price of oil. As already mentioned, the oil states have above-average values of per capita GSP in this period; hence, the covariance between the impact of the shock and initial per capita GSP is positive. As with the agricultural price shock of the 1920s, this property makes $\sigma_{\mathrm{t}}$ particularly sensitive to the shock (see equation [16]). The decline in $\sigma_{\mathrm{t}}$ after 1980 reflects the normal dynamics-assuming that $\sigma_{1980}$ is above the steady-state value, $\sigma$, in equation (14) -as well as the decline in the relative price of oil. 


\section{Comparisons with Findings across $\underline{\text { Countries }}$}

In this section we compare our findings for the U.S. states with analogous results across countries. It is well known that growth rates of real per capita GDP are uncorrelated with the starting level of real per capita GDP across a large group of countries in the post-World War II period. Barro (1991) uses the Summers-Heston (1988) data set along with other data to analyze the growth experiences of 98 countries from 1960 to 1985 . (The limitation to 98 countries, rather than the 114 market economies with Summers-Heston GDP data from 1960 to 1985, comes from the lack of information on variables other than GDP.) Table 5 , line 1 shows that a regression for the 98 countries in the form of equation (17) leads to the estimate, $\hat{\beta}=-.0037(.0018)$. The dependent variable is the growth rate of real per capita GDP from 1960 to 1985, $\Delta y_{1960,1985}$. The only independent variables are a constant and the log of 1960 per capita GDP, $\log \left(\mathrm{y}_{1960}\right)$. The main finding, also depicted in Figure 12, is the lack of a close relationship between $\Delta \mathrm{y}_{1960,1985}$ and $\log \left(\mathrm{y}_{1960}\right)$. In fact, the convergence coefficient $\hat{\beta}$ has the wrong sign; that is, there is a small tendency for the initially rich countries to grow faster than the poor ones after 1960 .

These cross-country results contrast sharply with the findings discussed earlier for the U.S. states. Figures 8,9 , and 11 and Tables 2 and 3 showed that, particularly over the longer samples, there is a clear and substantial negative correlation between starting per capita income or product and the subsequent growth rate. Line 5 of Table 5 uses a specification for the U.S. states that parallels the one used for the countries. The variables are based on gross state product over the time period, 1963-1986, and the regression includes only $\log \left(\mathrm{y}_{1963}\right)$ and a constant as regressors. The estimate in this case is $\hat{\beta}=.0218$ (.0053).

Barro (1991, Table I and Figure II) shows that a significantly negative partial relation between $\Delta \mathrm{y}_{1960,1985}$ and $\log \left(\mathrm{y}_{1960}\right)$ emerges for a large sample of countries if 
some other variables are held constant. The set of other variables for the 98 countries in the main results consists of primary and secondary school-enrollment rates in 1960, the average ratio of government consumption expenditure (exclusive of defense and education) to GDP from 1970 to 1985 , proxies for political stability based on numbers of revolutions, coups, and political assassinations, and a measure of market distortions based on purchasing-power-parity ratios for investment goods. If we include these variables for the 98 countries in the form of equation (17), then Table 5, line 2 shows that the estimated convergence coefficient becomes $\hat{\beta}=.0184$ (0045). (The additional variables are entered linearly into this regression.) This estimate of $\beta$ is no longer very much below the cross-state value shown in line 5 of the table.

From the perspective of equation (17), the theory predicts a negative relation between the initial level, $\log \left[\mathrm{y}\left(\mathrm{t}_{0}\right)\right]$, and the subsequent growth rate, $\Delta \mathrm{y}$, if we hold constant the steady-state position, $\log \left(\mathrm{y}^{*}\right)$, and the steady-state growth rate, $g$. (The constant $a$ in equation [17] depends on $\log \left(\hat{y}^{*}\right)$ and g.) Because the steady-state condition is $\mathrm{f}^{\prime}\left(\hat{\mathrm{k}}^{*}\right)=\rho+\delta$, the model implies that differences across economies in $\log \left(\hat{\mathrm{y}}^{*}\right)$ reflect differences in production functions and in the parameters $\rho$ and $\delta$. Variations in $\mathrm{g}$, the rate of technological progress (and hence, the long-run per capita growth rate), are not explained within this model. Some of the recent theories of endogenous growth, such as Romer (1990), suggest some determinants of $g$ (such as the costs of doing research, the nature of property rights in inventions, and the costs of absorbing new technologies). Note that, for a given value of $\log \left[y\left(t_{0}\right)\right]$, equation (17) implies that $\Delta y$ is increasing in $\log \left(\hat{y}^{*}\right)$ and $g$. Therefore, the theory implies that the relation between $\log \left[y\left(t_{0}\right)\right]$ and $\Delta y$ will be negative unless the correlation between $\log \left[y\left(t_{0}\right)\right]$ and the two omitted factors, $\log \left(\mathrm{y}^{*}\right)$ and $g$, is substantially positive.

The U.S. states are likely to be reasonably homogeneous with respect to the steady-state values, $\log \left(\mathrm{y}^{*}\right)$ and $\mathrm{g}$. That is, the differences in initial positions, $\log \left[\mathrm{y}\left(\mathrm{t}_{0}\right)\right]$, 
may be relatively much greater. (This condition is especially compelling if the initial differences reflect exogenous events, such as wars, world agricultural harvests, and oil shocks.) In this case, the negative relation between $\Delta \mathrm{y}$ and $\log \left[\mathrm{y}\left(\mathrm{t}_{0}\right)\right]$ would show up even if the differences in the steady-state values are not held constant. The result for $\beta$ shown in Table 5 , line 5 is consistent with this perspective.

On the other hand, the sample of 98 countries likely features large differences in the steady-state values, $\log \left(\mathrm{y}^{*}\right)$ and $\mathrm{g}$; that is, in the underlying parameters of technology and preferences that determine these long-run values. The correlation of $\log \left[y\left(t_{0}\right)\right]$ with $\log \left(\mathrm{y}^{*}\right)$ is likely to be substantially positive; that is, economies with higher steady-state values of output per effective worker would have followed a path that led them today to a higher level of output per person. Similarly, the correlation of $\log \left[y\left(t_{0}\right)\right]$ with $g$ is likely to be positive. Because of these correlations, the simple correlation between $\Delta y$ and $\log \left[y\left(t_{0}\right)\right]$ could be close to zero, as we found in the data. (This point is made by King and Rebelo [1989, pp 12-13].) On the other hand, if we include additional variables that hold constant some of the cross-country variations in $\log \left(\hat{y}^{*}\right)$ and $g$, then the partial relation between $\Delta y$ and $\log \left[y\left(t_{0}\right)\right]$ should become more negative. We interpret the additional variables that we added to the cross-country regression (Table 5 , line 2 ) in this manner. Accordingly, we view the estimate of $\beta$ in this regression-which is no longer very much below the values from the cross-state regressions-as coming closer to the theoretical convergence coefficient. 9

We can get further perspective on these arguments by considering a group of relatively homogeneous countries. We examine here the 20 original members of the

9The theory implies that the coefficient $\beta$ depends on some of the underlying parameters of preferences and technology. Hence, $\beta$ also varies across countries. On the other hand, there is no reason to expect a particular correlation between $\beta$ and the proportionate gap between output per effective worker and the steady-state value, $\log \left[\hat{y}\left(t_{0}\right) / \hat{y}^{*}\right]$. Therefore, our regressions may provide satisfactory estimates of the average $\beta$ for a group of countries. 
OECD. ${ }^{10}$ Table 5 , line 3 shows that the estimated convergence coefficient, $\dot{\beta}=.0095$ $(.0028)$, is significant and of the expected sign even when no additional variables are included. The magnitude is, however, about half that applicable to the U.S. states (Table 5, line 5). Our interpretation is that the OECD countries are intermediate between the $98-$ country group and the U.S. states in terms of the extent of cross-country variation in steady-state values, $\log \left(\hat{y}^{*}\right)$ and $g$, relative to the variation in initial positions, $\log \left[y\left(\mathrm{t}_{0}\right)\right]$. Line 4 of the table shows that the estimate for the OECD countries becomes $\hat{\beta}=.0203$ (.0068) when the additional variables discussed before are added to the regression. This result is very close to the estimate for the U.S. states, $.0218(.0053)$, in line 5 .

We have also explored in a preliminary way the addition of variables to the cross-state regressions. One variable that has a significantly positive influence is the fraction of the work force in 1960 that had accumulated some amount of college education. $"$ We added this variable along with the regional dummies and sectoral-composition variable, $\mathrm{S}^{\mathrm{i}}$, that we discussed before. Table 5 , line 6 shows that the estimated convergence coefficient becomes $\hat{\beta}=.0236$ (.0013). Thus, the inclusion of these other variables has a positive, but minor, effect on the estimate of $\beta$ across the U.S. states; $\hat{\beta}$ rises from .0218 on line 5 to .0236 on line 6 . Overall, the impact on $\hat{\beta}$ is greatest for the 98 countries (.0184 on line 2 versus -.0037 on line 1), next most important for the 20 OECD countries (.0203 on line 4 versus .0095 on line 3 ), and least important for the 48 U.S. states. These findings are consistent with the idea that first, the other variables help to hold constant cross-sectional differences in the long-run

${ }^{10}$ We exclude the four countries added after 1960 (Australia, Finland, Japan, and New Zealand) because of the possibility that the extension of membership was endogenous and related to the growth experience.

ItWe have not had much success in finding growth effects related to cross-state differences in government expenditures. Also, educational differences aside from college attainment were not important. 
values, $\log \left(\hat{y}^{*}\right)$ and $g$, and second, that the ranking of the extent of these differences (relative to the differences in initial levels of per capita income) goes from the 98 countries to the 20 OECD countries to the 48 U.S. states.

\section{$\underline{\sigma-\text { Convergence for Countries }}$}

Table 4 , column 3 shows that $\sigma_{\mathrm{t}}$, the standard deviation of the logarithm of real per capita GDP, for the 98 countries increased steadily from 1960 to 1985 . Column 4 of the table shows that $\sigma_{\mathrm{t}}$ also rose steadily from 1950 to 1985 for the 60 countries for which the data are available. (See Streissler [1979] for comparable results.) Not surprisingly, the level of these standard deviations is far greater than that shown in column 2 for GSP for the U.S. states. (The concepts are, however, not strictly comparable because the Summers-Heston (1988) numbers deflate each country's GDP by a PPP-based price deflator, whereas the cross-state numbers divide the nominal figures by a national price index.)

Column 5 of Table 4 shows that $\sigma_{\mathrm{t}}$ for the 20 OECD countries declined steadily from 1950 until the mid 1970s and then remained roughly stable from 1975 to 1985 . This behavior is broadly similar to that for the U.S. states (column 2), although the U.S. values are more variable after 1975. The level of $\sigma_{t}$ for the OECD countries is, not surprisingly, intermediate between that for the U.S. states and that for the 98 countries.

\section{Conclusions}

Our empirical results document the existence of $\beta$-convergence; that is, the tendency for economies that are further below the steady-state position to grow faster. This phenomenon shows up clearly for the U.S. states over various periods from 1840 to 1988. Over long samples, poor states tend to grow faster than rich states even if we do not hold constant any variables other than initial per capita income or product. If we 
hold constant the region and measures of sectoral composition, then the speed of convergence appears to be roughly the same-about 2 to $2-1 / 2$ percent per year-regardless of the time period or whether we consider personal income or gross state product.

We find evidence of $\beta$-convergence for a sample of 98 countries from 1960 to 1985 only if we hold constant a number of additional variables, such as school-enrollment rates in 1960 and the average ratio of government consumption spending to GDP. We interpret these variables as proxies for the steady-state ratio of output per effective worker and the steady-state per capita growth rate. If we hold constant these additional variables, then we estimate $\beta$-coefficients that are similar-roughly $2 \%$ per year-to those found for the U.S. states.

The standard neoclassical growth model with exogenous technological progress and a closed economy predicts $\beta$-convergence. To match our quantitative estimates, however, we have to assume underlying parameters for preferences and technology that depart substantially from standard benchmark cases. In particular, for reasonable values of the other parameters, the model requires a capital-share coefficient, $\alpha$, in the neighborhood of 0.8 . Lower values of $\alpha$, which imply that diminishing returns to capital set in more quickly, imply a more rapid rate of convergence than that revealed by the data.

Extensions of the neoclassical model to an open economy tend to speed up the process of convergence; the mobility of capital, labor, and technology implies that poor economies catch up faster to rich ones. Therefore, an open economy requires an even higher value of the capital-share parameter, $\alpha$, to match the empirical results.

Some recent models of endogenous economic growth, such as Rebelo (1990), assume constant returns to a broad concept of capital that includes human capital. This specification corresponds to $a=1.0$ in the neoclassical model. As mentioned, our 
empirical results indicate that the neoclassical model requires a value of $a$ of around 0.8 (or higher in the open-economy versions) to fit the observed speeds of convergence. The difference between $a=0.8$ - where diminishing returns to capital set in slowly-and $\alpha=1.0$ - where diminishing returns set in not at all-may seem to be minor. But, as shown in Table 1, the difference amounts to a half life of 27 years in the former case versus infinity in the latter. Thus, a value for $\alpha$ of 0.8 is very far from 1.0 in an economic sense.

In the open-economy versions of the neoclassical growth model it is possible to find convergence effects associated with technological diffusion even if the returns to capital are constant $(\alpha=1)$. (Recall that the convergence effects from the mobility of capital and labor depend on diminishing returns to capital.) Thus, we would like to break down the observed $\beta$-convergence into various components: first, effects related to diminishing returns to capital in the context of a closed economy; second, effects involving the mobility of capital and labor across economies; and third, effects that involve the gradual spread of technological improvements. The present empirical results, which exploit only cross-sectional differences in growth rates, do not allow us to separate the observed convergence patterns into these components. We hope to make these distinctions in future research, which will also exploit the time-series variations of growth rates. 


\section{References}

Barro, R.J., Macroeconomics, 1st edition, Wiley, New York, 1984.

Barro, R.J., "Economic Growth in a Cross Section of Countries," Quarterly Journal of Economics, 106, 1991.

Baumol, W.J., "Productivity Growth, Convergence, and Welfare: What the Long Run Data Show," American Economic Review, 76, December 1986, 1072-1085.

Blanchard, O.J. and S. Fischer, Lectures on Macroeconomics, M.I.T. Press, Cambridge MA, 1989.

Borjas, G., Friends or Strangers: The Impact of Immigrants on the U.S. Economy, Basic Books, New York, 1990.

Borts, G.H. and J.L. Stein, Economic Growth in a Free Market, Columbia University Press, New York, 1964.

Bureau of Economic Analysis, State Personal Income by State: 1929-1982, U.S. Government Printing Office, Washington D.C., 1986.

Cass, D., "Optimum Growth in an Aggregative Model of Capital Accumulation," Review of Economic Studies, 32, July 1965, 233-240.

De Long, J.B., "Productivity Growth, Convergence, and Welfare: Comment," American Economic Review, 78, December 1988, 1138-1154.

Dowrick, S. and D. Nguyen, "OECD Comparative Economic Growth 1950-85: Catch-Up and Convergence," American Economic Review, 79, December 1989, 1010-1030.

Easterlin, R.A. , "Regional Growth of Income: Long Run Tendencies," in S. Kuznets and D. Thomas; eds., Population Redistribution and Economic Grouth in the United States, The American Philosophical Society, Philadelphia, 1957. 
Easterlin, R.A., "Interregional Differences in Per Capita Income, Population, and Total Income, 1840-1950," in Conference on Research in Income and Wealth, NBER Studies in Income and Wealth, v. 24, 1960.

Jorgenson, D.W. and K. Yun, "Tax Policy and Capital Allocation," Scandinavian Journal of Economics, 88, 1986, 355-377.

Jorgenson, D.W. and K. Yun, "Tax Reform and U.S. Economic Growth," Journal of Political Economy, 98, 1990.

King, R.G. and S.T. Rebelo, "Transitional Dynamics and Economic Growth in the Neoclassical Model," National Bureau of Economic Research working paper no. 3185, November 1989.

Koopmans, T.C., "On the Concept of Optimal Growth," in The Econometric Approach to Development Planning, North Holland, Amsterdam, 1965.

Maddison, A., "Growth and Slowdown in Advanced Capitalist Economies: Techniques of Quantitative Assessment," Journal of Economic Literature, 25, June 1987, 649-698.

Nelson, R.R. and E.S. Phelps, "Investment in Humans, Technological Diffusion, and Economic Growth," American Economic Review, Papers and Proceedings, 56, May $1966,69-82$.

Ramsey, F.P., "A Mathematical Theory of Saving," Economic Journal, 38, December $1928,543-559$.

Rebelo, S.T., "Long Run Policy Analysis and Long Run Growth," National Bureau of Economic Research working paper, April 1990.

Renshaw, V., E. Trott and H. Friedenberg, "Gross State Product by Industry, 1963-1986," U.S. Survey of Current Business, 68, March 1988.

Romer, P.M., "Increasing Returns and Long Run Growth," Journal of Political Economy, 94, October 1986, 1002-1037. 
Romer, P.M., "Endogenous Technological Change," Journal of Political Economy, 98,1990 .

Sala i Martin, X., "Lecture Notes on Economic Growth," unpublished, Harvard University, November 1989.

Sala i Martin, X., On Growth and States, unpublished Ph.D. dissertation, Harvard University, 1990.

Solow, R.M., "A Contribution to the Theory of Economic Growth," Quarterly Journal of Economics, 70, February 1956, 65-94.

Streissler, E., "Growth Models as Diffusion Processes: II. Empirical Implications," Kyklos, 32, no. 3, 1979, 571-586.

Summers, R. and A. Heston, "A New Set of International Comparisons of Real Product and Price Levels: Estimates for 130 Countries," The Review of Income and Wealth, 34, March 1988, 1-25. 
Table 1

Theoretical Convergence Coefficient, $\beta$

$\begin{array}{lcc}a & \beta \text { (per year) } & \text { half- } 1 \text { ife (years) } \\ 0.05 & 0.498 & 1.4 \\ 0.10 & 0.332 & 2.1 \\ 0.15 & 0.254 & 2.7 \\ 0.20 & 0.207 & 3.4 \\ 0.25 & 0.173 & 4.0 \\ & & \\ 0.30 & 0.147 & 4.7 \\ 0.35 & 0.126 & 5.5 \\ 0.40 & 0.109 & 6.4 \\ 0.45 & 0.094 & 7.4 \\ 0.50 & 0.081 & 8.6 \\ & & \\ 0.55 & 0.070 & 10.0 \\ 0.60 & 0.059 & 11.7 \\ 0.65 & 0.050 & 13.9 \\ 0.70 & 0.041 & 16.8 \\ 0.75 & 0.033 & 20.9 \\ & & \\ 0.80 & 0.026 & 26.9 \\ 0.85 & 0.019 & 36.8 \\ 0.90 & 0.012 & 56.4 \\ 0.95 & 0.006 & 114.7 \\ 1.00 & 0.000 & \infty\end{array}$

Notes: The value for the convergence coefficient, $\beta$, comes from equation (10) using the indicated value of the capital-share parameter, $a$, and the baseline values for the other parameters: $\rho=.05$ per year, $\delta=.05$ per year, $n=.02$ per year, $g=.02$ per year, and $\theta=1$. The half-life is the number of years for $\log \left(\mathrm{y}_{\mathrm{t}}\right)$ to move halfway from the initial value, $\log \left[\hat{y}\left(t_{0}\right)\right]$, to the steady-state value, $\log \left(\hat{y}^{*}\right)$. 
Table 2

Cross-State Regressions for Personal Income

\begin{tabular}{|c|c|c|c|c|c|}
\hline & Sample & $\hat{\beta}$ & $\begin{array}{l}\text { Sectoral } \\
\text { Comp. }\left(\mathrm{S}^{\mathrm{i}}\right)\end{array}$ & $\mathrm{R}^{2}$ & $\hat{\sigma}$ \\
\hline 1. & $1880-1988$ & $\begin{array}{l}.0175 \\
(.0046)\end{array}$ & - & 0.92 & .0014 \\
\hline 2. & $1930-1988$ & $\begin{array}{l}.0143 \\
(.0028)\end{array}$ & - & 0.85 & .0019 \\
\hline 3. & $1880-1900$ & $(.0224)$ & -. & 0.62 & .0054 \\
\hline 4 & $1900-1920$ & $\begin{array}{l}.0209 \\
(.0063)\end{array}$ & - & 0.67 & .0062 \\
\hline 5. & $1920-1930$ & $\begin{array}{l}-.0122 \\
(.0074)\end{array}$ & -. & 0.43 & .0111 \\
\hline 6. & $1930-1940$ & $(.0127)$ & - & 0.36 & .0075 \\
\hline 7. & $1940-1950$ & $\begin{array}{l}.0373 \\
(.0053)\end{array}$ & - & 0.86 & .0057 \\
\hline 8. & $1950-1960$ & $\begin{array}{l}.0202 \\
(.0052)\end{array}$ & - & 0.49 & .0048 \\
\hline 9. & $1960-1970$ & $\begin{array}{l}.0135 \\
(.0043)\end{array}$ & - & 0.68 & .0037 \\
\hline 10. & $1970-1980$ & $\begin{array}{l}.0119 \\
(.0069)\end{array}$ & - - & 0.36 & .0056 \\
\hline 11. & $1980-1988$ & $\begin{array}{l}-.0005 \\
(.0114)\end{array}$ & -- & 0.51 & .0103 \\
\hline 12 . & $\begin{array}{l}9 \text { - period, } \\
\beta \text { restricted }\end{array}$ & $\begin{array}{l}.0189 \\
(.0019)\end{array}$ & - & \multicolumn{2}{|c|}{$\begin{array}{l}-2 \cdot \log (\lambda)=32.1 \\
5 \% \text { crit. val. }=15.5\end{array}$} \\
\hline 13. & $1880-1900$ & $\begin{array}{l}.0268 \\
(.0048)\end{array}$ & $\begin{array}{l}-0.0161 \\
(0.0079)\end{array}$ & 0.65 & .0053 \\
\hline 14. & $1900-1920$ & $\begin{array}{l}.0269 \\
(.0075)\end{array}$ & $\begin{array}{l}-0.0214 \\
(0.0094)\end{array}$ & 0.71 & .0060 \\
\hline 15. & $1920-1930$ & $\begin{array}{l}.0218 \\
(.0112)\end{array}$ & $\begin{array}{l}-0.0936 \\
(0.0175)\end{array}$ & 0.64 & .0089 \\
\hline
\end{tabular}


Table 2, continued

\begin{tabular}{|c|c|c|c|c|c|}
\hline & Sample & $\beta$ & $\begin{array}{l}\text { Sectoral } \\
\text { Comp. }\left(\mathrm{S}^{\mathrm{i}}\right)\end{array}$ & $\mathrm{R}^{2}$ & $\hat{\sigma}$ \\
\hline 16. & $1930-1940$ & $\begin{array}{l}.0141 \\
(.0048)\end{array}$ & $\begin{array}{c}2.43 \\
(0.81)\end{array}$ & 0.46 & .0070 \\
\hline 17 . & $1940-1950$ & $\begin{array}{l}.0362 \\
(.0055)\end{array}$ & $\begin{array}{l}-0.40 \\
(0.57)\end{array}$ & 0.87 & .0057 \\
\hline 18 & $1950-1960$ & $\begin{array}{l}.0313 \\
(.0055)\end{array}$ & $\begin{array}{c}0.42 \\
(0.09)\end{array}$ & 0.65 & .0041 \\
\hline 19. & $1960-1970$ & $\begin{array}{l}.0194 \\
(.0052)\end{array}$ & $\begin{array}{c}0.55 \\
(0.25)\end{array}$ & 0.71 & .0036 \\
\hline 20. & $1970-1980$ & $\begin{array}{l}.0139 \\
(.0076)\end{array}$ & $\begin{array}{c}0.25 \\
(0.37)\end{array}$ & 0.36 & .0056 \\
\hline 21 & $1980-1988$ & $\begin{array}{l}.0196 \\
(.0106)\end{array}$ & $\begin{array}{l}1.35 \\
(0.22)\end{array}$ & 0.73 & .0077 \\
\hline 22. & $\begin{array}{l}9-\text { period, } \\
\beta \text { restricted }\end{array}$ & $\begin{array}{l}.0249 \\
(.0021)\end{array}$ & indiv. & $\begin{array}{l}-2 \cdot \log (\lambda)= \\
5 \% \text { crit. val. }\end{array}$ & $\begin{array}{l}13.9 \\
=15.5\end{array}$ \\
\hline 23 & $1930-1988$ & $\begin{array}{l}.0207 \\
(.0049)\end{array}$ & $\begin{array}{c}0.34 \\
(0.14)\end{array}$ & 0.87 & .0018 \\
\hline 24 & $1840-1880$ & $\begin{array}{l}.0254 \\
(.0067)\end{array}$ & -- & 0.91 & .0030 \\
\hline
\end{tabular}

Notes: Standard errors of coefficients are shown in parentheses. The regression that begins in 1840 has 29 observations and those that beg in in 1880 have 47 observations. All others have 48 observations. The dependent variable is the growth rate of real per capita personal income exclusive of transfers over the indicated sample period. Each regression includes a constant and three regional dummy variables, south, midwest, west. (The 1840-1880 regression includes only south and midwest.) The coefficient $\hat{\beta}$ applies to $\log \left[\mathrm{y}\left(\mathrm{t}_{0}\right)\right]$, where $\mathrm{y}\left(\mathrm{t}_{0}\right)$ is real per capita personal income at the start of the period. The sectoral composition variable, $\mathrm{S}^{\mathrm{i}}$, is described in the text. The regressions denoted 9 period, $\beta$ restricted use weighted least squares with the coefficient $\beta$ constrained to be equal for all nine sub-periods. Individual coefficients are estimated for each sub-period for the constant, regional dummies, and the sectoral composition variable. The likelihood-ratio statistic refers to the hypothesis of equality for the $\beta$ coefficients. Under the null, this statistic is distributed as a $\chi^{2}$ with 8 d.f. 
Table 3

Cross-State Regressions for Gross State Product

\begin{tabular}{|c|c|c|c|c|c|}
\hline & Sample & $\hat{\beta}$ & $\begin{array}{l}\text { Sectoral } \\
\text { Comp. }\left(S^{i}\right)\end{array}$ & $\mathrm{R}^{2}$ & $\hat{\sigma}$ \\
\hline 1. & 1963- 1986 & $\begin{array}{l}.0180 \\
(.0059)\end{array}$ & - & 0.48 & .0038 \\
\hline 2. & 1963- 1969 & $\begin{array}{l}.0154 \\
(.0060)\end{array}$ & - & 0.63 & .0056 \\
\hline 3. & $1969-1975$ & $\begin{array}{l}.0406 \\
(.0162)\end{array}$ & -- & 0.41 & .0120 \\
\hline 4. & $1975-1981$ & $\begin{array}{l}-.0285 \\
(.0130)\end{array}$ & - & 0.17 & .0139 \\
\hline 5. & $1981-1986$ & $\begin{array}{l}.1130 \\
(.0244)\end{array}$ & -- & 0.62 & .0168 \\
\hline 6. & $\begin{array}{l}4 \text { - period, } \\
\beta \text { restricted }\end{array}$ & $\begin{array}{l}.0211 \\
(.0053)\end{array}$ & -. & $\begin{array}{l}-2 \cdot \log (\lambda)= \\
5 \% \text { crit. val. }\end{array}$ & $\begin{array}{l}31.2 \\
=7.8\end{array}$ \\
\hline 7. & 1963- 1969 & $\begin{array}{l}.0157 \\
(.0060)\end{array}$ & $\begin{array}{c}0.18 \\
(0.25)\end{array}$ & 0.63 & .0056 \\
\hline 8. & $1969-1975$ & $\begin{array}{l}.0297 \\
(.0101)\end{array}$ & $\begin{array}{l}1.56 \\
(0.20)\end{array}$ & 0.74 & .0081 \\
\hline 9. & $1975-1981$ & $\begin{array}{l}.0258 \\
(.0108)\end{array}$ & $\begin{array}{l}1.74 \\
(0.15)\end{array}$ & 0.78 & .0072 \\
\hline 10 & $1981-1986$ & $\begin{array}{l}.0238 \\
(.0091)\end{array}$ & $\begin{array}{c}1.73 \\
(0.13)\end{array}$ & 0.92 & .0079 \\
\hline 11. & $\begin{array}{l}\text { 4-period, } \\
\beta \text { restricted }\end{array}$ & $\begin{array}{l}.0216 \\
(.0042)\end{array}$ & indiv. & $\begin{array}{l}-2 \cdot \log (\lambda)= \\
5 \% \text { crit. val. }\end{array}$ & $\begin{array}{l}1.7 \\
=7.8\end{array}$ \\
\hline 12 . & $1963-1986$ & $\begin{array}{l}.0222 \\
(.0065)\end{array}$ & $\begin{array}{c}0.63 \\
(0.27)\end{array}$ & 0.54 & .0036 \\
\hline
\end{tabular}

Notes: All regressions have 48 observations. The regressions denoted 4 -period, $\beta$ restricted use weighted least squares with the coefficient $\beta$ constrained to be equal for the four sub-periods. Under the null of equal coefficients, the likelihood-ratio statistic is distributed as a $\chi^{2}$ with 3 d.f. See also the notes to Table 2. 
Table 4

Unweighted Standard Deviations, $\sigma_{t}$, of Logs of Income and Product

(3)

(4)

(5)

Year Pers. Inc. U.S. states

GSP

GDP

GDP

GDP

\begin{tabular}{|c|c|c|c|c|c|c|}
\hline . & U.S. & states & U.S. states & 98 countries & 60 countries & 20 OECD \\
\hline 1840 & 0.30 & (29 obs) & - - & -- & -- & - - \\
\hline 1880 & 0.37 & $(29$ obs) & -- & -- & -- & $\cdots$ \\
\hline 1880 & 0.54 & (47 obs) & -- & -- & -- & -- \\
\hline 1900 & 0.47 & (48 obs) & - & -- & -- & -- \\
\hline 1920 & 0.33 & $"$ & -- & -- & -- & -- \\
\hline 1930 & 0.40 & $"$ & -. & - - & -- & - - \\
\hline 1940 & 0.36 & $"$ & - & - - & -- & -- \\
\hline 1945 & 0.24 & $"$ & -- & -- & -- & -- \\
\hline 1950 & 0.24 & $"$ & $-\therefore$ & - - & 0.89 & 0.60 \\
\hline 1955 & 0.22 & $"$ & - & -- & 0.91 & 0.55 \\
\hline 1960 & 0.21 & $" 1$ & -- & 0.93 & 0.93 & 0.53 \\
\hline 1963 & 0.19 & 11 & 0.18 & 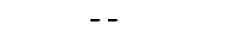 & -- & -- \\
\hline 1965 & 0.18 & $1 "$ & 0.17 & 0.99 & 0.95 & 0.50 \\
\hline 1970 & 0.17 & $"$ & 0.15 & 1.00 & 0.98 & 0.45 \\
\hline 1975 & 0.15 & 11 & 0.14 & 1.02 & 0.99 & 0.42 \\
\hline 1980 & 0.15 & $"$ & 0.17 & 1.07 & 1.03 & 0.42 \\
\hline 1985 & 0.17 & $"$ & 0.15 & 1.12 & 1.06 & 0.43 \\
\hline 1986 & 0.18 & $"$ & 0.14 & -- & - - & -- \\
\hline 1988 & 0.19 & $"$ & -- & -- & -- & -- \\
\hline
\end{tabular}

Notes: The table indicates the cross-sectional standard deviation, $\sigma_{t}$, of the logarithm of the indicated concept of income or product. Column 1 applies to real per capita state personal income exclusive of transfers for the U.S. states. The first two observations, for 1840 and 1880 , refer to 29 states or territories. The next observation, also for 1880 , refers to 47 states or territories. Values from 1900 on refer to 48 states or territories. Column 2 applies to real per capita gross state product (GSP) for 48 U.S. states. Column 3 refers to real per capita GDP for the 98 countries studied in Barro (1991). Column 4 uses the 60 countries for which data on GDP are available since 1950 . Column 5 applies to the 20 original OECD countries; see the notes to Table 5 for a listing of the countries. 
Table 5

Comparison of Regressions across Countries and U.S. States

\begin{tabular}{|c|c|c|c|c|c|}
\hline & Sample & $\hat{\beta}$ & $\begin{array}{l}\text { Additional } \\
\text { Variables }\end{array}$ & $\mathrm{R}^{2}$ & $\hat{\sigma}$ \\
\hline 1. & $\begin{array}{l}98 \text { countries } \\
1960-1985\end{array}$ & $\begin{array}{l}-.0037 \\
(.0018)\end{array}$ & no & 0.04 & .0183 \\
\hline 2. & " & $\begin{array}{l}.0184 \\
(.0045)\end{array}$ & yes & 0.52 & .0133 \\
\hline 3. & $\begin{array}{l}20 \text { OECD Countries } \\
1960-1985\end{array}$ & $\begin{array}{l}.0095 \\
(.0028)\end{array}$ & no & 0.45 & .0051 \\
\hline 4. & $"$ & $\begin{array}{l}.0203 \\
(.0068)\end{array}$ & yes & 0.69 & .0046 \\
\hline 5. & $\begin{array}{l}48 \text { U.S. states } \\
1963-1986\end{array}$ & $\begin{array}{l}.0218 \\
(.0053)\end{array}$ & no & 0.38 & .0040 \\
\hline 6. & $"$ & $\begin{array}{l}.0236 \\
(.0013)\end{array}$ & yes & 0.61 & .0033 \\
\hline
\end{tabular}

Notes: The dependent variable in regressions $1-4$ is the growth rate of real per capita GDP from 1960 to 1985 ; in regressions 5 and 6 it is the growth rate of real per capita GSP from 1963 to 1986 . The coefficient $\beta$ applies in regressions 1-4 to the logarithm of real per capita GDP in 1960; in regressions 5 and 6 to the logarithm of real per capita GSP in 1963. Each regression also includes a constant. The additional variables included in regressions 2 and 4 are the primary and secondary school-enrollment rates in 1960 , the average ratio of government consumption expenditure (standard figures less spending on defense and education) to GDP from 1970 to 1985, the average number of revolutions and coups per year from 1960 to 1985 , the average number of political assassinations per capita per year from 1960 to 1985, and the average deviation from unity of the Summers-Heston (1988) purchasing-power-parity ratio for investment in 1960 . See Barro (1991) for details on these variables. The additional explanatory variables included in regression 6 are regional dummies, the sectoral-composition variable, $\mathrm{s}^{\mathrm{i}}$, and the fraction of workers in 1960 that had accumulated some amount of college education. The $20 \mathrm{OECD}$ countries (the original membership in 1960) are Austria, Belgium, Canada, Denmark, France, Germany, Greece, Iceland, Ireland, Italy, Luxembourg, Netherlands, Norway, Portugal, Spain, Sweden, Switzerland, Turkey, United Kingdom, and United States. 


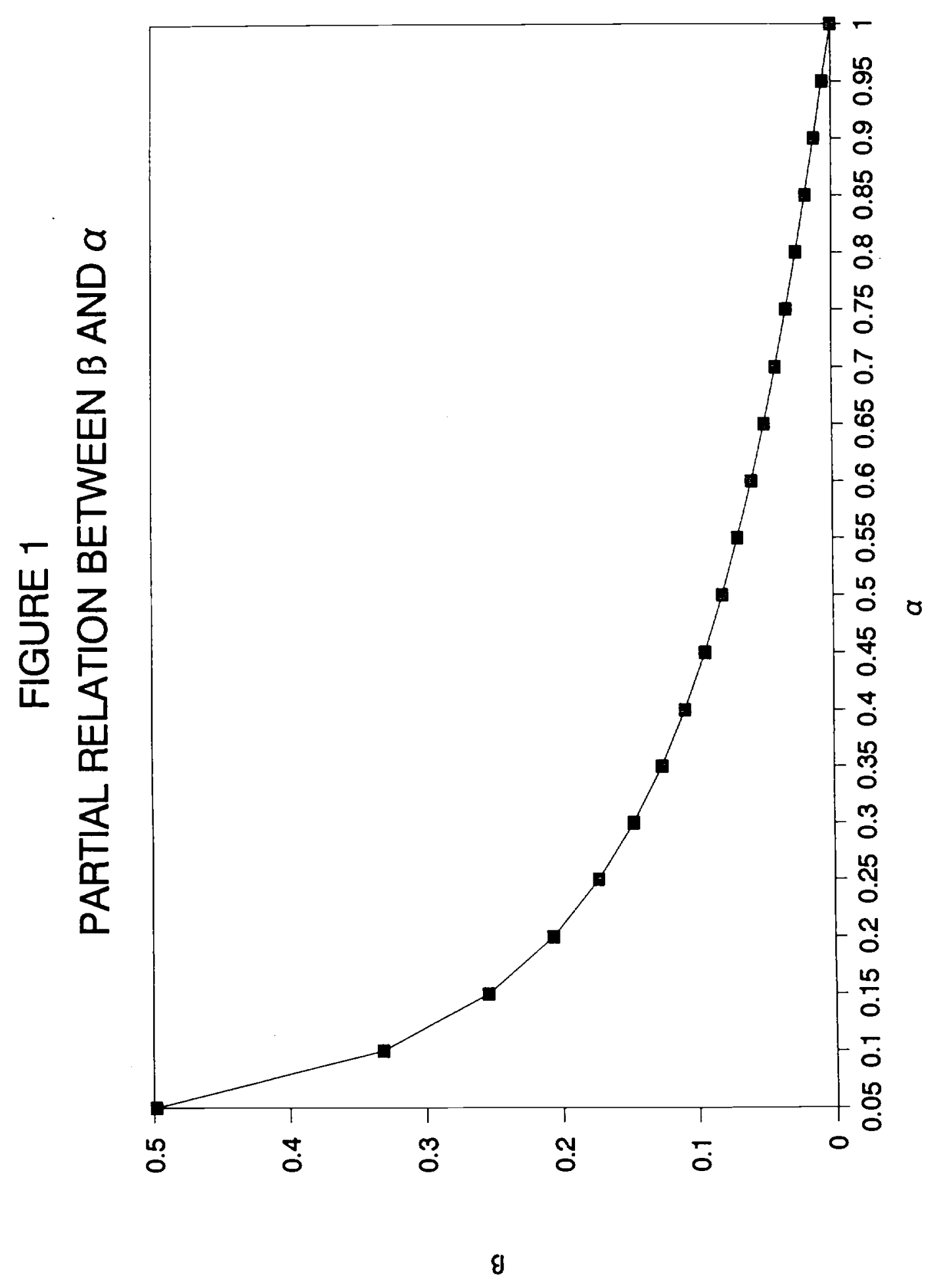




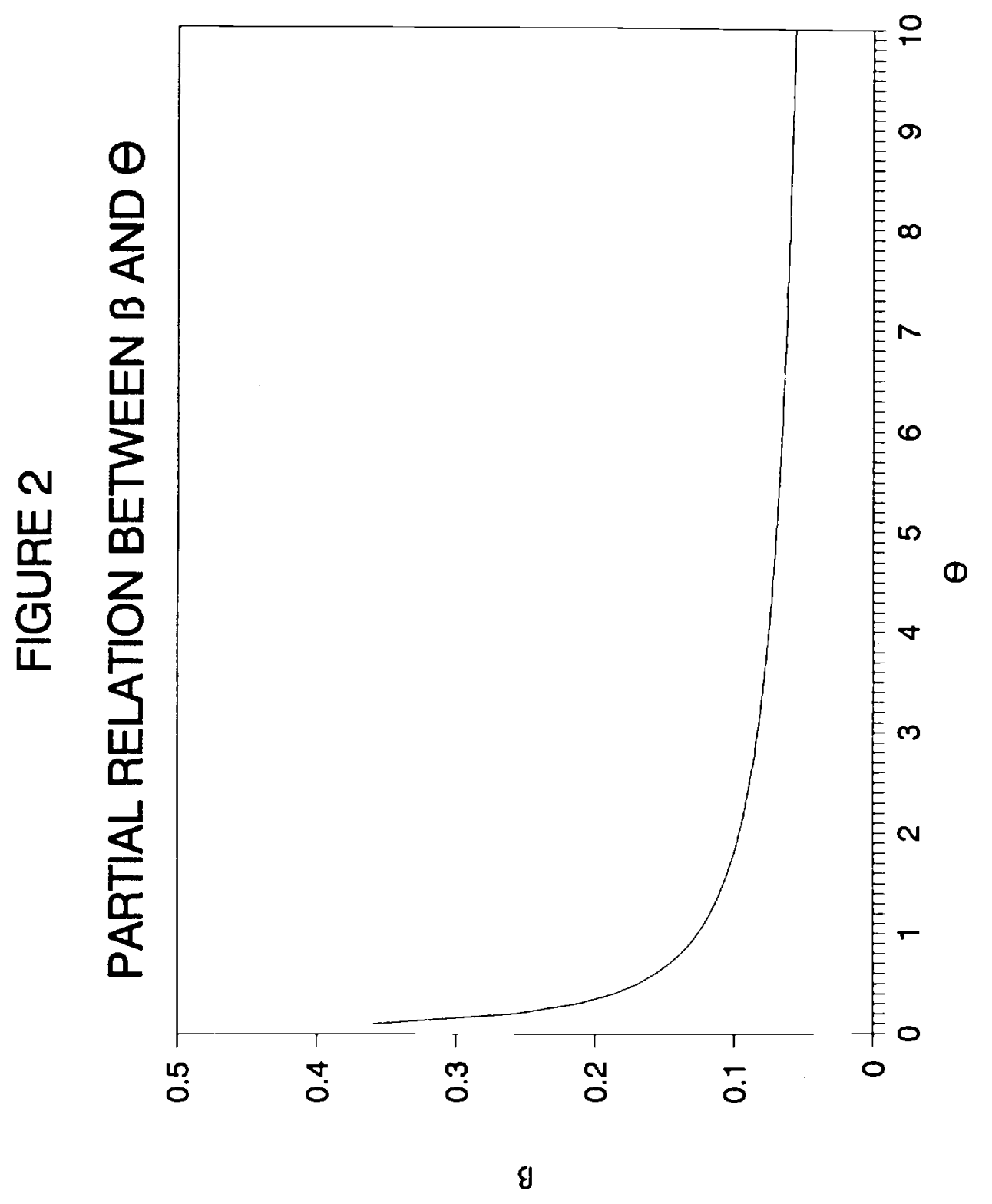




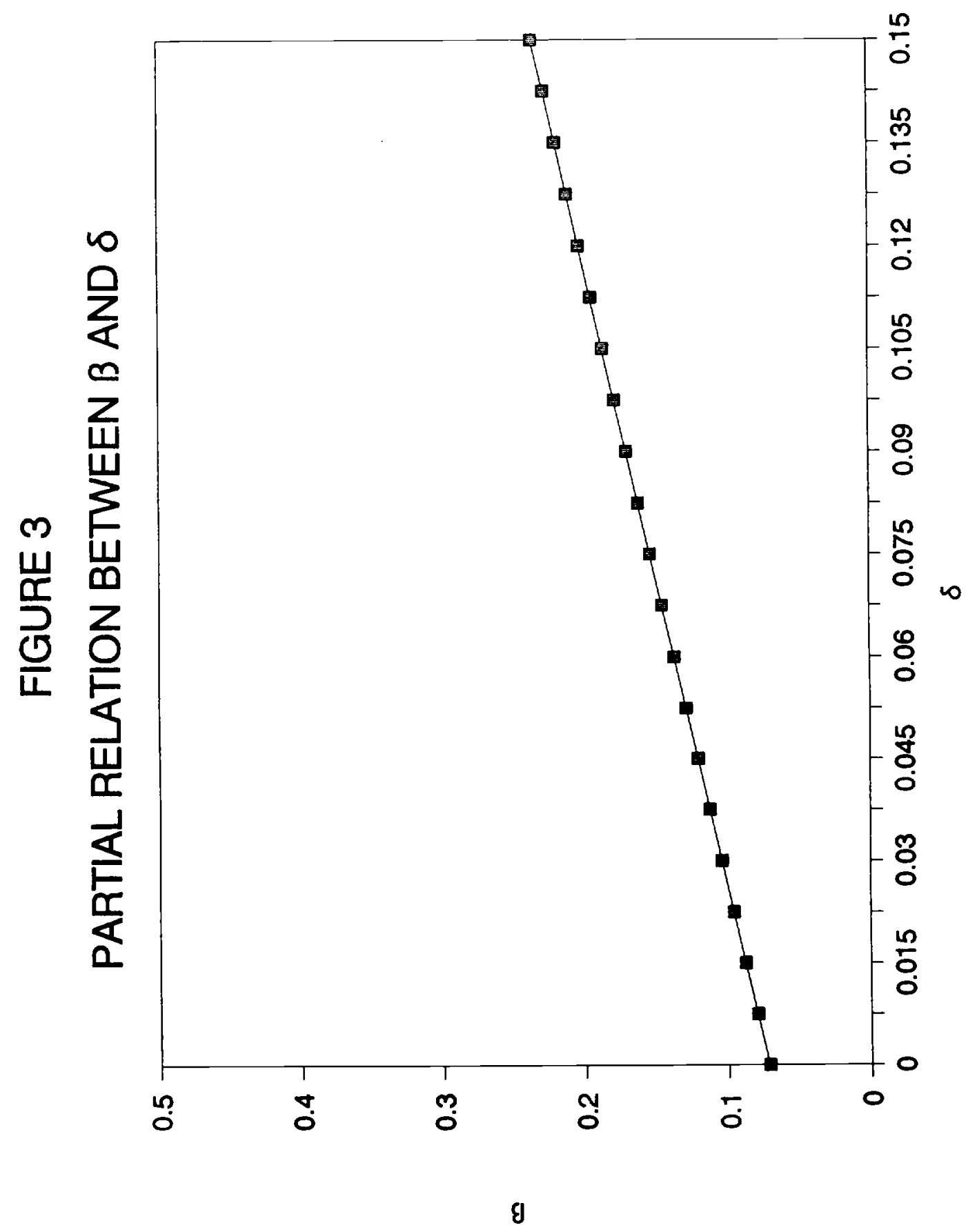




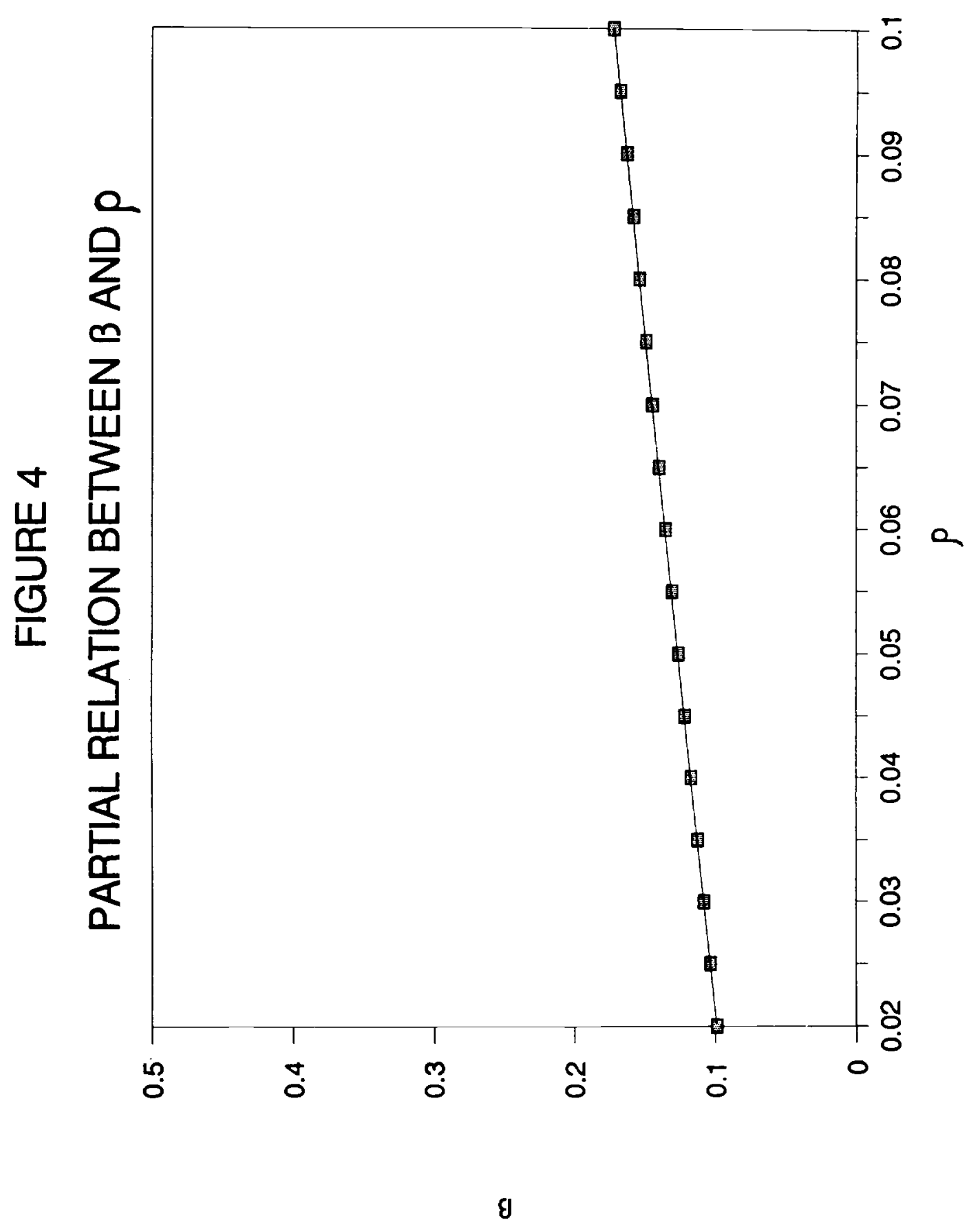




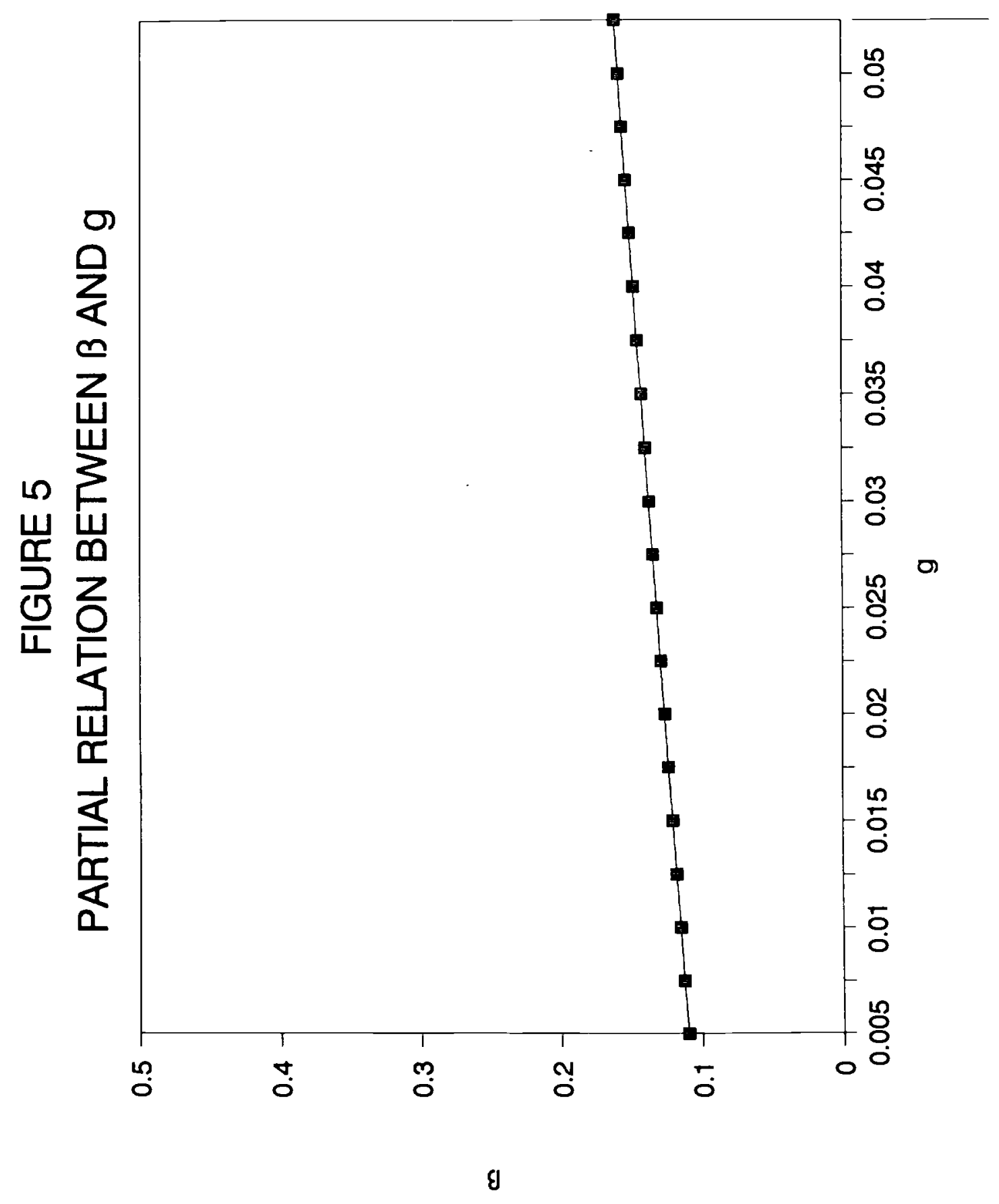




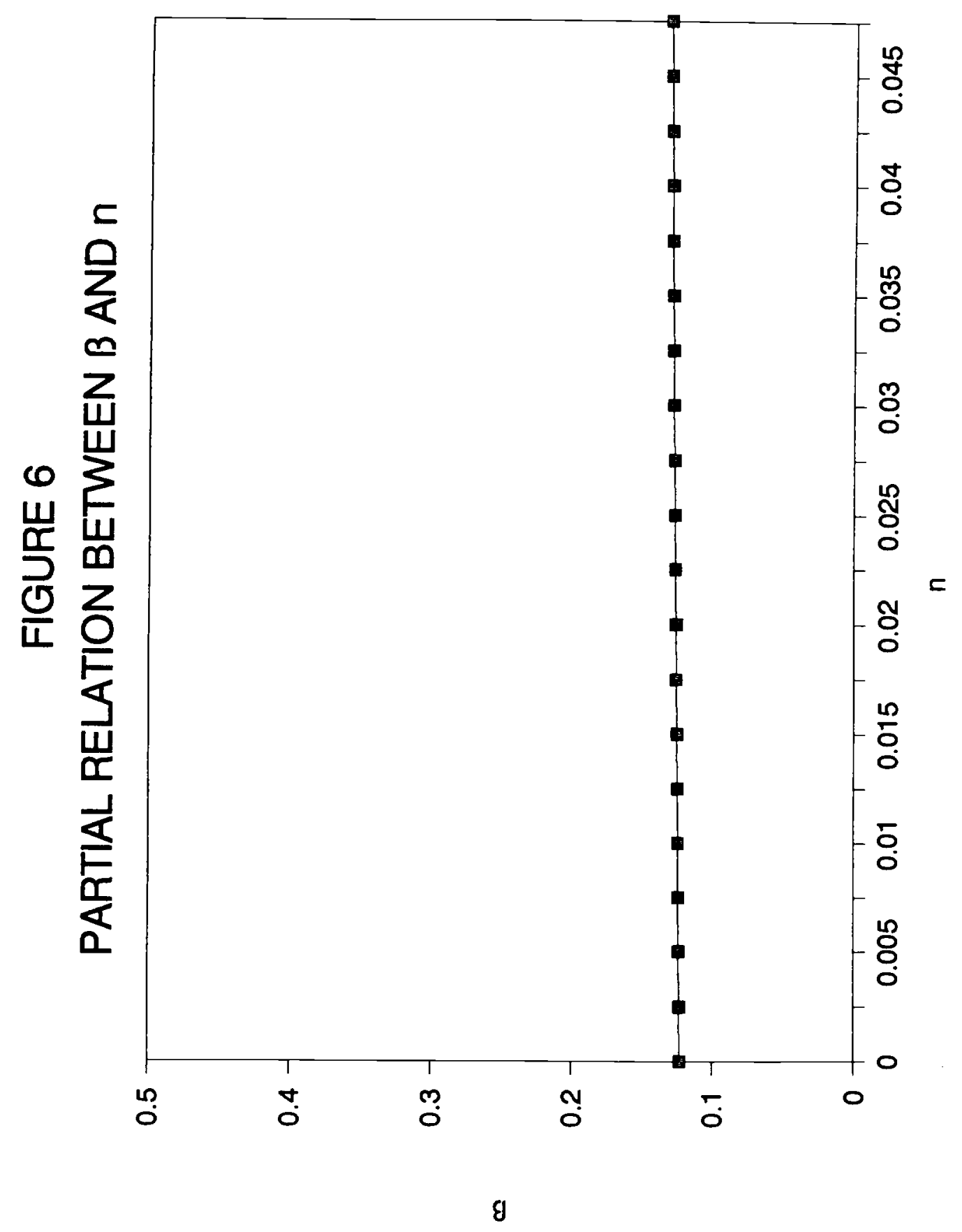




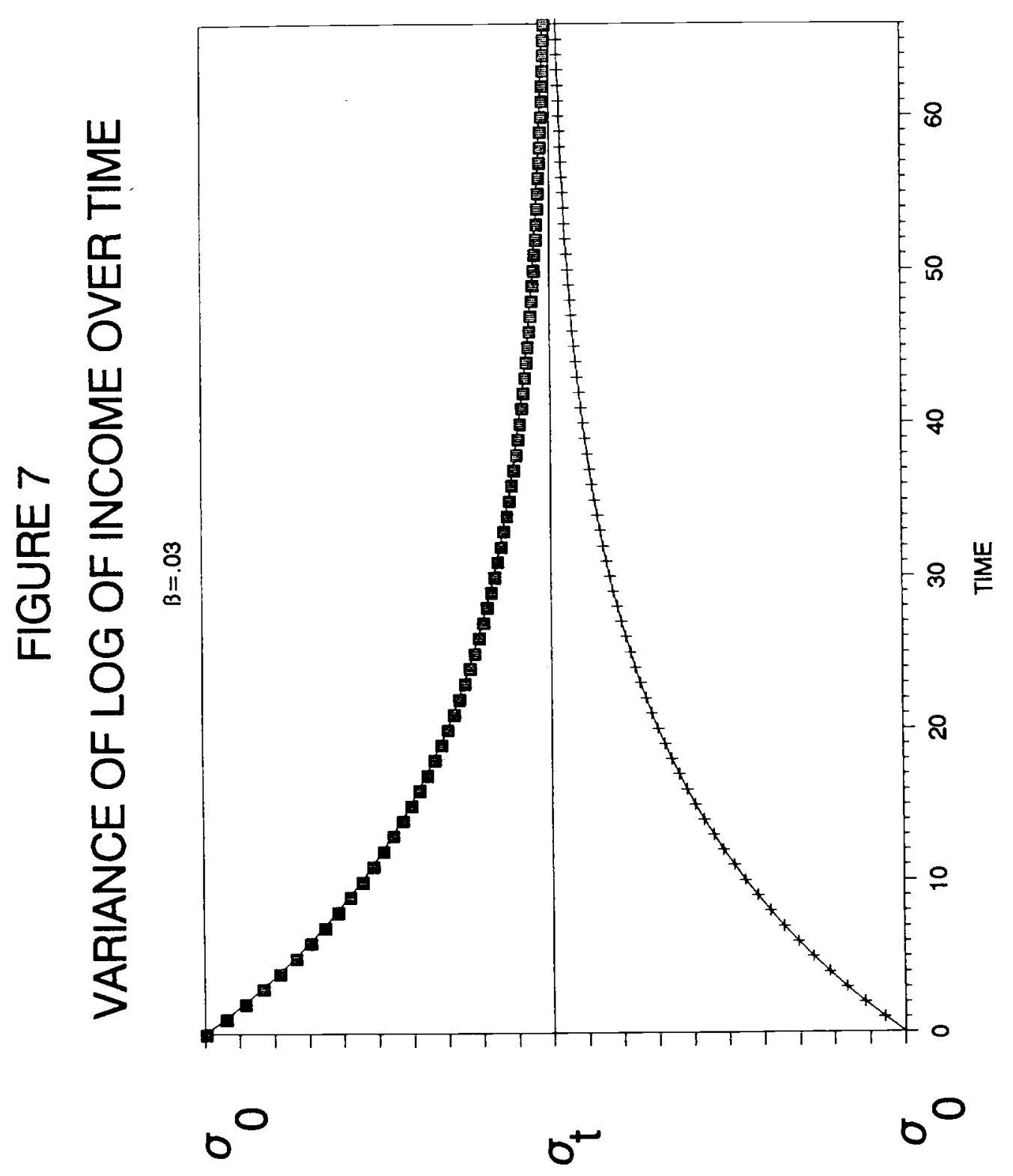




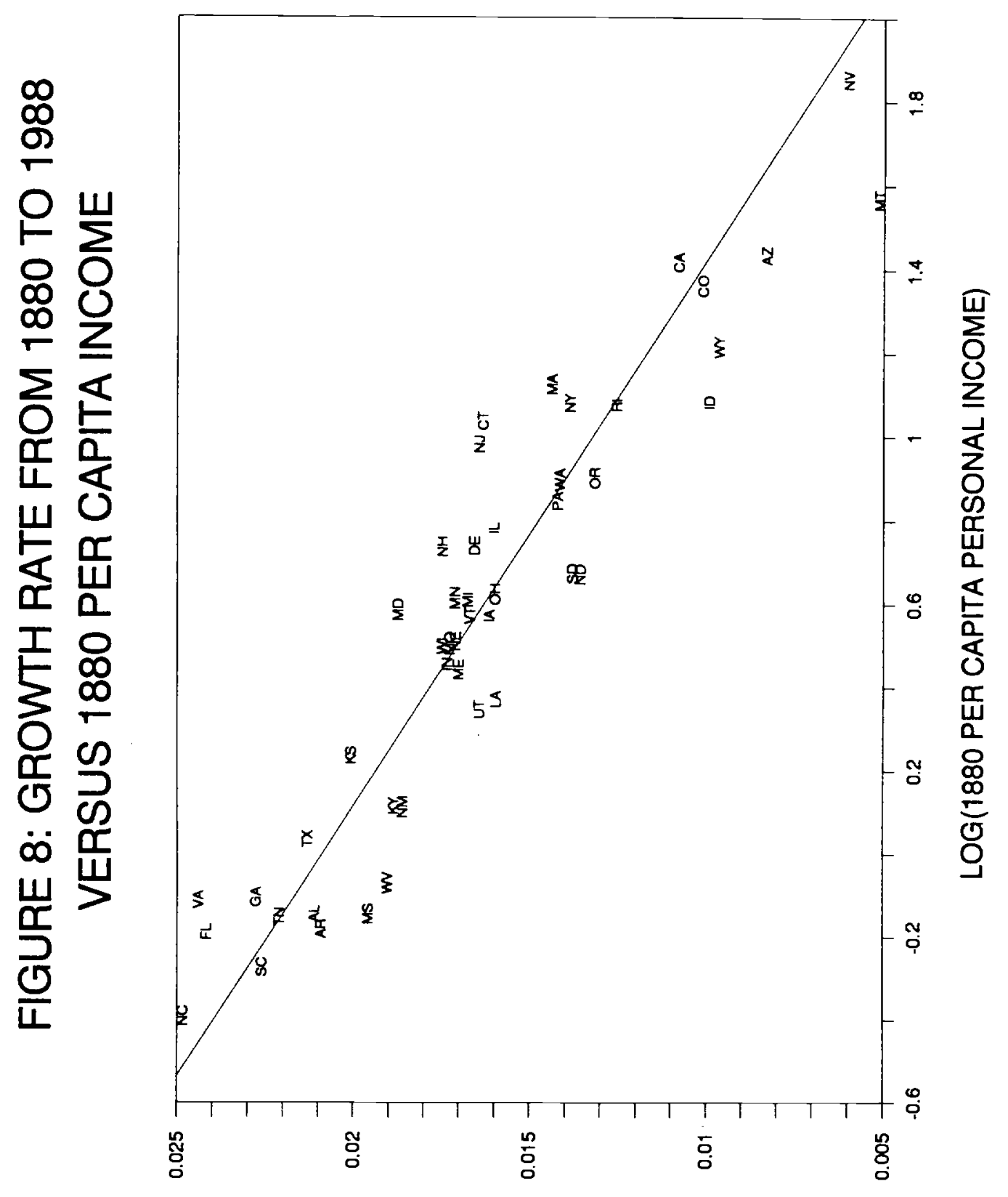

886L-088L' $\exists \perp \forall \forall$ HLMOY९ $\forall \perp l d \forall O ~ y \exists d$ 


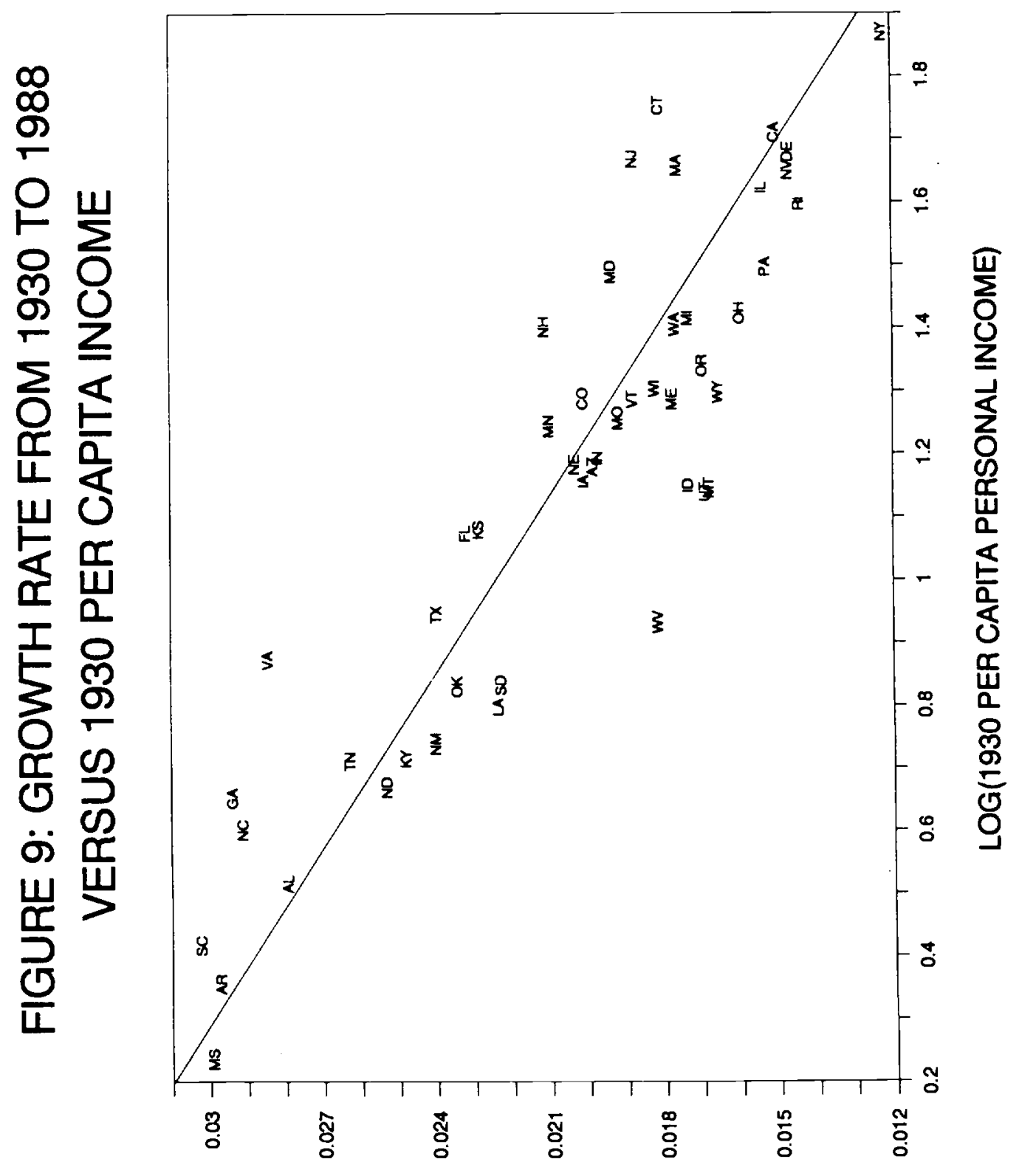

886เ-0ع6เ ' $\exists \perp \forall Y H \perp M O \forall ९ \forall \perp I d \forall O ~ \forall \exists d$ 


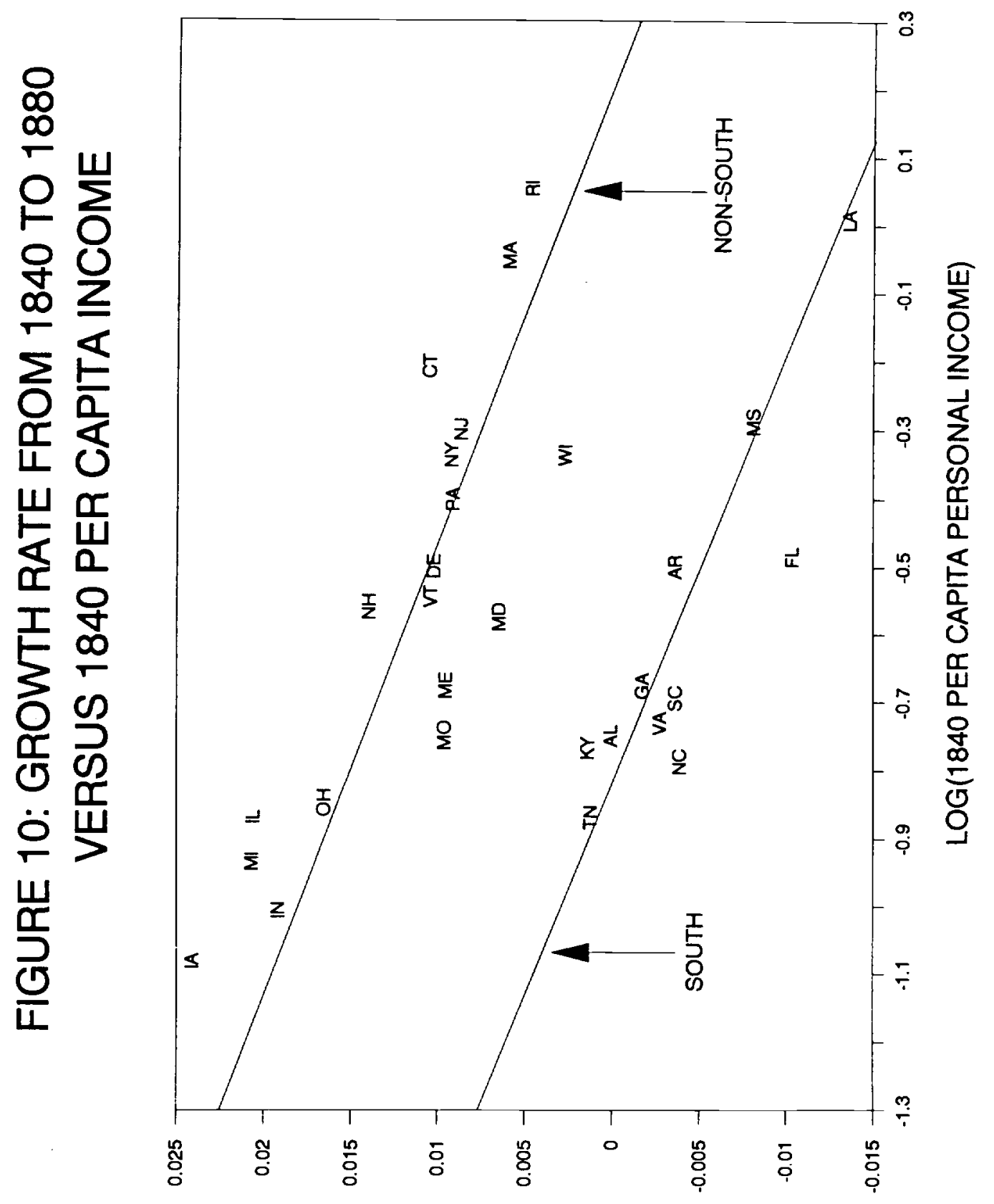

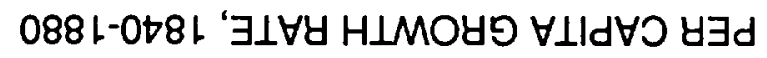




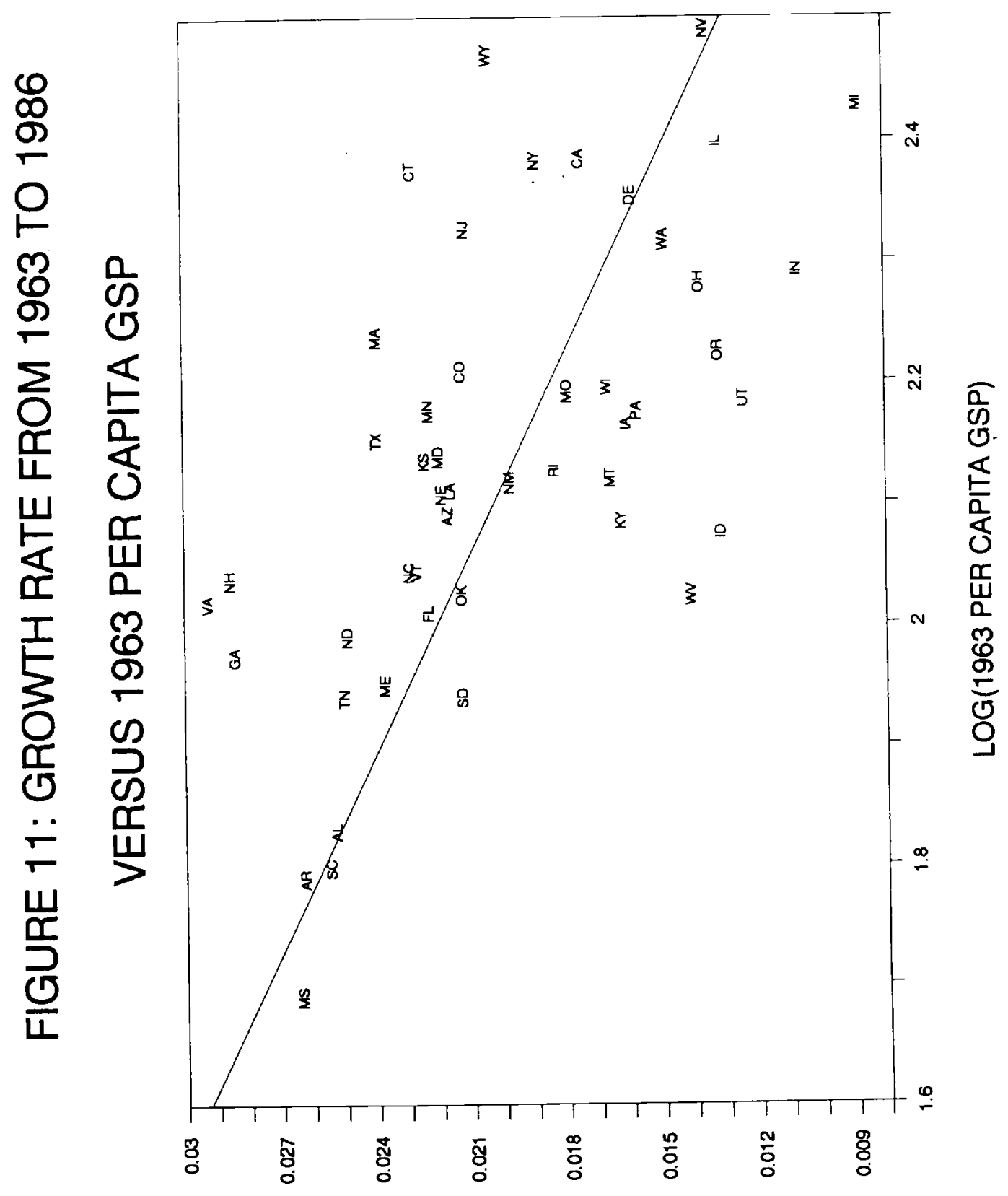

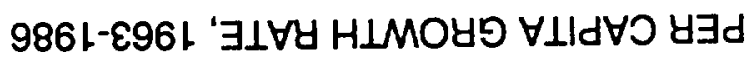




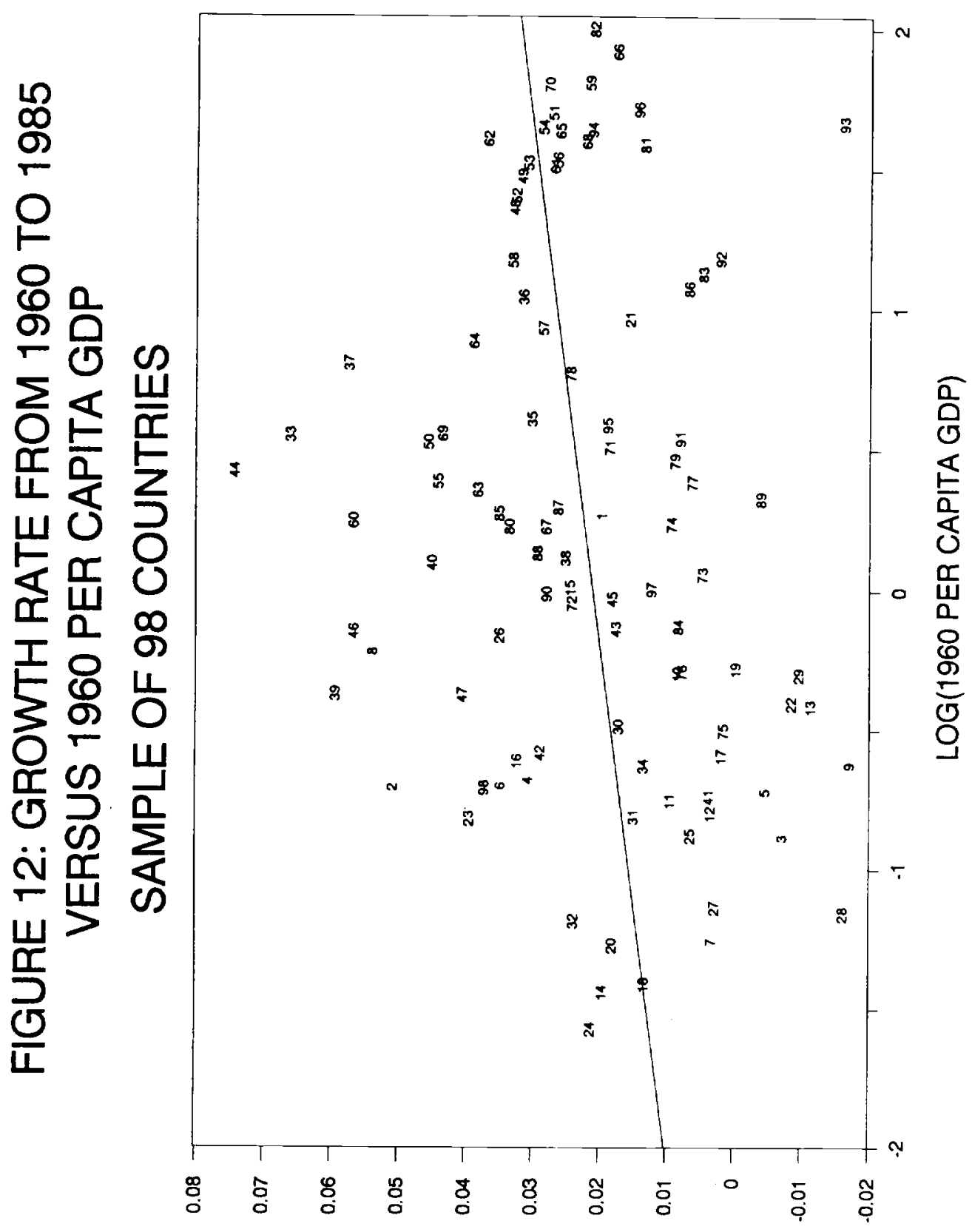

S86เ-096เ' $\exists \perp \forall \forall$ HLMOY९ $\forall \perp l d \forall O ~ \forall \exists d$ 


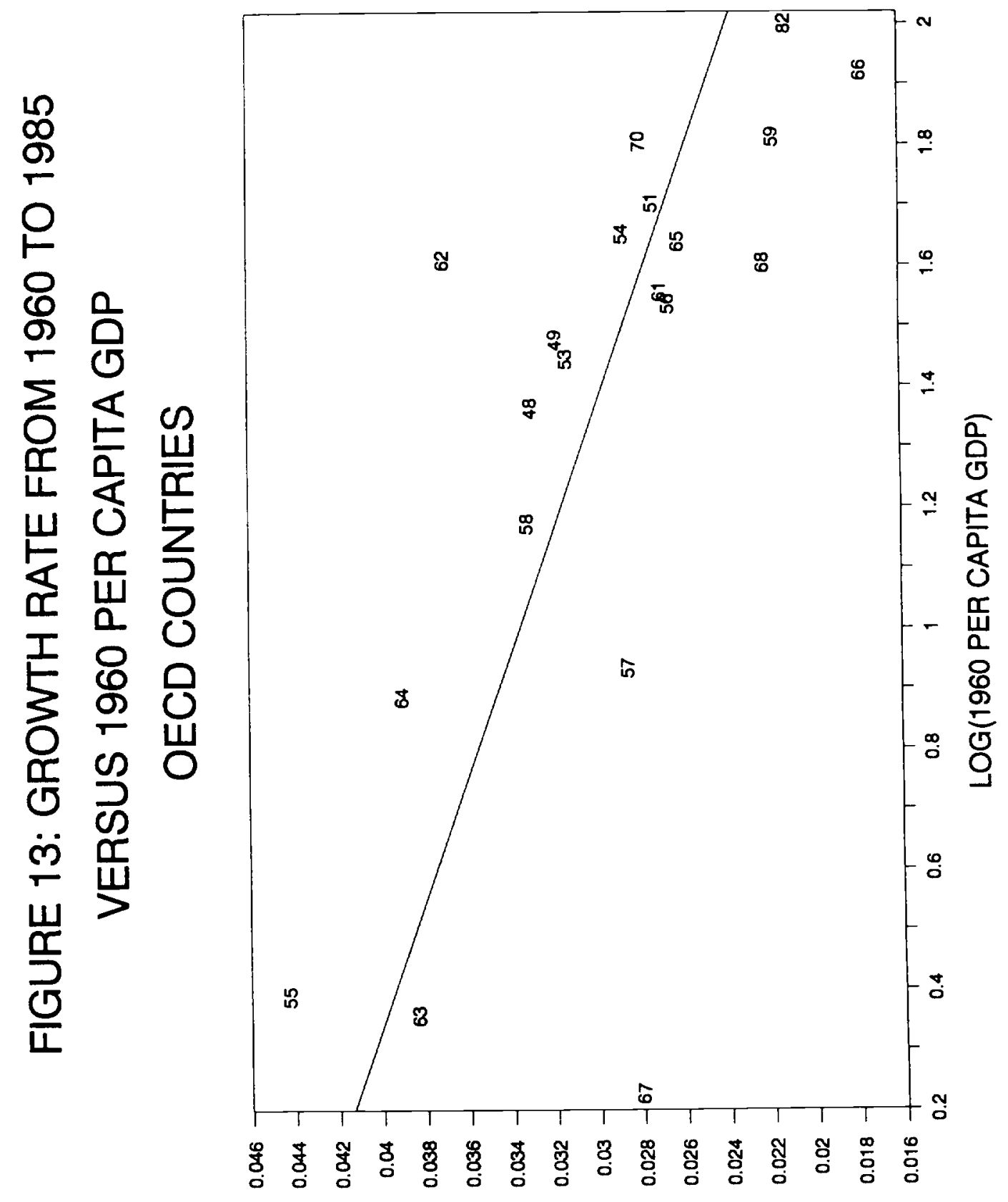

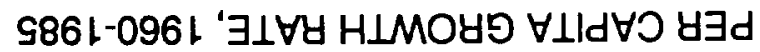


Key for Countries in Figures 12 and 13
1. Algeria
36. Israel
71. Costa Rica
2. Botswana
37. Japan
38. Jordan
39. Korea
4. Cameroon
40. Malaysia
72. Dominican Republic
5. Central Afr. Repub.
41. Nepal
6. Egypt
42. Pakistan
43. Phillipines
44. Singapore
45. Sri Lanka
73. El Salvador
74. Guatemala
75. Haiti
8. Gabon
9. Ghana
10. Ivory Coast
46. Taiwan
47. Thailand
12. Liberia
13. Madagascar
14. Malawi
15. Mauritius
48. Austria
49. Belgium
50. Cyprus
76. Honduras
77. Jamaica
78. Mexico
79. Nicaragua
80. Panama
16. Morocco
17. Nigeria
51. Denmark
52. Finland
18. Rwanda
19. Senegal
20. Sierra Leone
53. France
54. Germany
55. Greece
81. Trinidad \& Tobago
82. United States
83. Argentina
84. Bolivia
85. Brazil
86. Chile
87. Colombia
88. Ecuador
89. Guyana
90. Paraguay
21. South Africa
22. Sudan
23. Swaziland
24. Tanzania
25. Togo
56. I celand
57. Ireland
58. Italy
59. Luxembourg
60. Malta
91. Peru
92. Uruguay
93. Venezuela
94. Australia
95. Fiji
26. Tunesia
61. Netherlands
96. New Zealand
27. Uganda
28. Zaire
29. Zambia
30. Zimbabwe
62. Norway
63. Portugal
97. Papua New Guinea
98. Indonesia
31. Bangladesh
64. Spain
65 . Sweden
66. Switzerland
32. Burma
33. Hong Kong
34. India
35. Iran
67. Turkey
68. United Kingdom
69. Barbados
70. Canada 